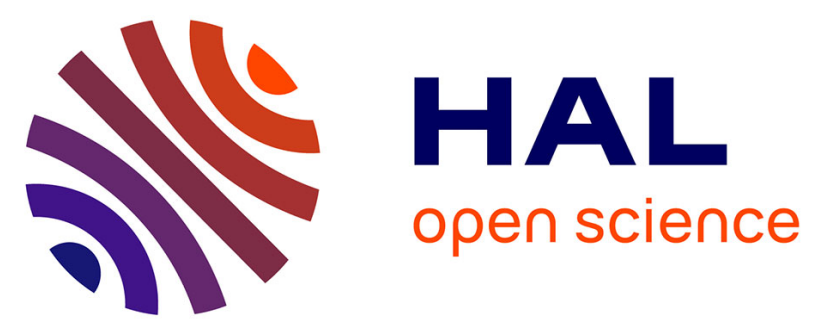

\title{
A XANES and EPMA study of Fe $3+$ in chlorite: substitutions, importance of oxychlorite and implications for cation site distribution and thermobarometry
}

Lorella Masci, Benoît Dubacq, Anne Verlaguet, Christian Chopin, Vincent de Andrade, Clément Herviou

\section{- To cite this version:}

Lorella Masci, Benoît Dubacq, Anne Verlaguet, Christian Chopin, Vincent de Andrade, et al.. A XANES and EPMA study of Fe 3+ in chlorite: substitutions, importance of oxychlorite and implications for cation site distribution and thermobarometry. American Mineralogist, 2019, 104 (3), pp.403-417. 10.2138/am-2019-6766 . hal-02187082

\section{HAL Id: hal-02187082 \\ https://hal.sorbonne-universite.fr/hal-02187082}

Submitted on 29 Aug 2019

HAL is a multi-disciplinary open access archive for the deposit and dissemination of scientific research documents, whether they are published or not. The documents may come from teaching and research institutions in France or abroad, or from public or private research centers.
L'archive ouverte pluridisciplinaire HAL, est destinée au dépôt et à la diffusion de documents scientifiques de niveau recherche, publiés ou non, émanant des établissements d'enseignement et de recherche français ou étrangers, des laboratoires publics ou privés. 


\title{
A XANES and EPMA study of $\mathrm{Fe}^{3+}$ in chlorite: Importance of oxychlorite and implications for cation site distribution and thermobarometry
}

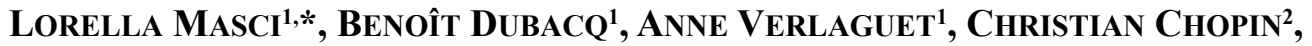 \\ VINCENT DE ANDRADE ${ }^{3}$, AND ClÉMENT HERVIOU ${ }^{1}$
}

\author{
${ }^{1}$ Sorbonne Université, CNRS-INSU, Institut des Sciences de la Terre Paris, ISTeP UMR 7193, 75005 Paris, France \\ ${ }^{2}$ Laboratoire de Géologie, Ecole normale supérieure, CNRS, UMR8538, PSL Research University, 24 rue Lhomond, 75005 Paris, France \\ ${ }^{3}$ Advanced Photon Source, Argonne National Laboratory, Argonne, Illinois 60439, U.S.A.
}

\begin{abstract}
Chlorite is a ubiquitous product of metamorphism, alteration of magmatic rocks and hydrothermal processes owing to its large stability field and wide compositional range. Its composition is governed by several substitutions and has been used as a geothermometer, on the basis of empirical, semi-empirical, and thermodynamic models. As in some other phyllosilicates of petrological interest, the oxidation state of iron in chlorite may differ from the usually assumed divalent state. However, the crystal chemistry of trivalent iron in chlorite remains poorly known, and the thermodynamic properties of ferric chlorite are missing from databases used for petrological modeling. As part of an attempt to fill this gap, we present results from in situ, micrometer-scale measurements of the oxidation state of iron in various chlorite-bearing samples. X-ray absorption near-edge spectroscopy (XANES) was combined with electron probe microanalysis (EPMA) on the same crystals. Results show iron oxidation states varying from ferrous to ferric; iron is in octahedral coordination in all ferromagnesian chlorites but to $\sim 25 \%$ tetrahedral in the lithian chlorite cookeite $\left(1.0 \mathrm{wt} \% \mathrm{Fe}_{2} \mathrm{O}_{3 \text { (total })}\right)$. Absolute amounts of ferric iron cover an unprecedented range $\left(0\right.$ to $\sim 30 \mathrm{wt} \% \mathrm{Fe}_{2} \mathrm{O}_{3}$ ). For highly magnesian, ferric chlorite, $\mathrm{Fe}$ concentrations are low and can be accounted for by $\mathrm{Al}=\mathrm{Fe}^{3+}$ substitution. In Fe-rich samples, $\mathrm{Fe}^{3+}$ may exceed 2 atoms per formula unit (pfu, 18 oxygen basis). When structural formulas are normalized to 28 charges corresponding to the standard $\mathrm{O}_{10}(\mathrm{OH})_{8}$ anionic basis, these measurements define the exchange vector of a di-trioctahedral-type substitution: $3^{\mathrm{VI}}\left(\mathrm{Mg}, \mathrm{Fe}^{2+}\right)={ }^{\mathrm{V}} \mathrm{\square}+2{ }^{\mathrm{Vl}} \mathrm{Fe}^{3+}$, as described in earlier studies. However, structural formulas calculated on the basis of the oxygen contents actually measured by EPMA show that this trend is an artifact, due to the neglect of variations in the number of protons in the structure. Our measurements indicate increasing hydrogen deficiency with increasing $\mathrm{Fe}^{3+}$ content, up to $\sim 2 \mathrm{H}^{+}$pfu in the $\mathrm{Fe}^{3+}$-rich chlorite samples, corresponding to a net exchange vector of the type $\mathrm{R}^{2+}+\mathrm{H}^{+}=\mathrm{Fe}^{3+}$. These results do not support substitutions toward di-trioctahedral ferric endmembers, and highlight the need for considering substitution toward an "oxychlorite" (i.e., H-deficient) ferric component, close to tri-trioctahedral, with an $\mathrm{O}_{12}(\mathrm{OH})_{6}$ anionic basis, even in green, pristine-looking chlorite. The effects of iron oxidation and $\mathrm{H}$ deficiency on chlorite geothermometers were explored. They are deterring if $\mathrm{H}$ deficiency is ignored but, given the sensitivity of most thermometers to octahedral vacancy, the assumption $\mathrm{Fe}_{\text {total }}=\mathrm{Fe}^{2+}$ is still safer than using high measured $\mathrm{Fe}^{3+}$ contents and the standard 28 charge basis, which artificially increases vacancies. In such ferric chlorites, EPMA measurement of oxygen allows a fair estimate of $\mathrm{H}$ content if $\mathrm{Fe}^{3+} / \mathrm{Fe}^{2+}$ is known; it should be more systematically implemented. For the same reasons, literature data reporting $\mathrm{Fe}^{3+}$-rich chlorite with vacancy content along the possibly artificial di-trioctahedral-type substitution should be verified. With the help of constraints from thermodynamic models, charge balance, crystal symmetry, and proton loss, a new cation site distribution is proposed for di-tri- to tri-trioctahedral chlorites in the $\mathrm{Fe}^{2+}-\mathrm{Fe}^{3+}-\mathrm{Mg}-\mathrm{Al}-\mathrm{Si}-\mathrm{O}-\mathrm{H}$ system, allowing a more realistic thermodynamic handling of their solid solutions.

Keywords: Chlorite, oxychlorite, hydrogen deficiency, XANES, EPMA, ferric iron incorporation, geothermometry, solid solution, cation site distribution
\end{abstract}

\section{INTRODUCTION}

Chlorite is a ubiquitous phyllosilicate characterized by a $14 \AA c$ cell-parameter that is found in a wide range of geological environments and crystallizes from diagenesis conditions up to blueschist- and amphibolite-facies metamorphic conditions. This $14 \AA$ value reflects the combination of a TOT mica-like layer (a partially hydroxylated octahedral sheet between two

\footnotetext{
*E-mail: lorella.masci@sorbonne-universite.fr
}

opposing tetrahedral sheets) with an interlayer hydroxide sheet ("brucitic" octahedral sheet) in which each oxygen atom is part of a hydroxyl group involved in hydrogen bonding to the facing 2:1 layer (Fig. 1). Both octahedral sheets may be fully or partly occupied, leading to tri-tri-, di-tri-, and di-di-octahedral chlorite end-members. Zazzi et al. (2006) and Beaufort et al. (2015) offered extensive reviews of the structure and crystal chemistry of chlorite. The usual site assignment of cations in the chlorite structure is recalled in Table 1, together with a list of the potential end-members referred to in this and previous studies. 


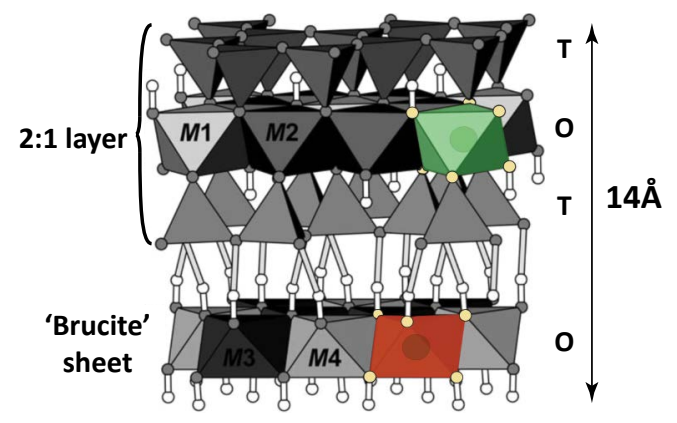

FIGURE 1. Structure of chlorite, after Zazzi et al. (2006). Gray (or yellow) spheres are oxygen atoms; white spheres are $\mathrm{H}$ atoms. An M1 site (in the TOT layer) and an M3 site (in the hydroxide interlayer, "brucite sheet") are highlighted in color.

Chlorite is used as a geothermometer because its composition varies with its crystallization temperature via several solid solutions. Empirical and semi-empirical equations establish a link between temperature and the amount of, e.g., tetrahedral $\mathrm{Al}$ (Cathelineau 1988), octahedral vacancies (Hillier and Velde 1991) or, in addition, Mg contents (Inoue et al. 2009; Bourdelle et al. 2013a). Thermodynamic models are also available (e.g., Walshe 1986; Holland et al. 1998; Vidal et al. 2001; Lanari et al. 2014); they use end-members (of which some are fictive) with fixed thermodynamic properties and activity models for solid solutions, some considering ordering and reciprocal solid solutions. These models are based on the structure and composition of chamosite (a tri-trioctahedral chlorite solid solution among the clinochlore, Mg-amesite, and "daphnite" end-members, e.g., Holland and Powell 1998) extended to the end-members "Al-free chlorite" (e.g., Holland et al. 1998), sudoite [the di-trioctahedral chlorite $\square \mathrm{Mg}_{2} \mathrm{Al}_{3}\left(\mathrm{Si}_{3} \mathrm{Al}\right) \mathrm{O}_{10}(\mathrm{OH})_{8}$, Vidal et al. 2001], and Feamesite (Vidal et al. 2005). These models account for three main substitutions observed in chlorite: (1) homovalent Fe-Mg substitution $\mathrm{Fe}=\mathrm{Mg}$; (2) the di-trioctahedral substitution ${ }^{\mathrm{V}} \mathrm{\square}+$ $2{ }^{\mathrm{VI}} \mathrm{Al}=3^{\mathrm{VI}}\left(\mathrm{Mg} \mathrm{Fe}^{2+}\right)$ where ${ }^{\mathrm{VI}} \square$ is an octahedral vacancy, and (3) the Tschermak substitution ${ }^{\mathrm{IV}} \mathrm{Si}+{ }^{\mathrm{VI}}\left(\mathrm{Mg}, \mathrm{Fe}^{2+}\right)={ }^{\mathrm{IV}} \mathrm{Al}+{ }^{\mathrm{VI}} \mathrm{Al}$ (e.g., Zane et al. 1998). The Al-free chlorite end-member is used to account for compositions with $\mathrm{Si} / \mathrm{Al}$ ratio greater than that of clinochlore (3/1). The need for a di-dioctahedral "pyrophyllitegibbsite" end-member has been mentioned (Inoue et al. 2009), yet its thermodynamic properties remain unknown.

TABLE 1. Cation site distribution for chlorite end-members, after Vidal et al. (2001), Bourdelle and Cathelineau (2015), and additional studies referenced in the table

\begin{tabular}{|c|c|c|c|c|c|c|}
\hline & $(\mathrm{T} 1)_{2}$ & $(\mathrm{~T} 2)_{2}$ & M1 & $(\mathrm{M} 2)_{2}$ & $(\mathrm{M} 3)_{2}$ & M4 \\
\hline Daphnite/Clinochlore & $(\mathrm{Si})_{2}$ & Si Al & $\mathrm{Fe}^{2+}, \mathrm{Mg}$ & $\left(\mathrm{Fe}^{2+}, \mathrm{Mg}\right)_{2}$ & $\left(\mathrm{Fe}^{2+}, \mathrm{Mg}\right)_{2}$ & $\mathrm{Al}$ \\
\hline (Fe, Mg)-Amesite & $(\mathrm{Si})_{2}$ & $(\mathrm{Al})_{2}$ & $\mathrm{Al}$ & $\left(\mathrm{Fe}^{2+}, \mathrm{Mg}\right)_{2}$ & $\left(\mathrm{Fe}^{2+}, \mathrm{Mg}\right)_{2}$ & $\mathrm{Al}$ \\
\hline (Fe, Mg)-Sudoite & $(\mathrm{Si})_{2}$ & Si Al & $\square$ & $(\mathrm{Al})_{2}$ & $\left(\mathrm{Fe}^{2+}, \mathrm{Mg}\right)_{2}$ & $\mathrm{Al}$ \\
\hline Al-free chlorite & $(\mathrm{Si})_{2}$ & $(\mathrm{Si})_{2}$ & $\mathrm{Fe}^{2+}, \mathrm{Mg}$ & $\left(\mathrm{Fe}^{2+}, \mathrm{Mg}\right)_{2}$ & $\left(\mathrm{Fe}^{2+}, \mathrm{Mg}\right)_{2}$ & $\mathrm{Fe}^{2+}, \mathrm{Mg}$ \\
\hline "Pyrophyllite-Gibbsite" & $(\mathrm{Si})_{2}$ & $(\mathrm{Si})_{2}$ & $\square$ & $(\mathrm{Al})_{2}$ & $(\mathrm{Al})_{2}$ & $\square$ \\
\hline $\begin{array}{l}\text { Ferri-sudoite (Vidal } \\
\text { et al. 2016) }\end{array}$ & $(\mathrm{Si})_{2}$ & Si Al & $\square$ & $(\mathrm{Al})_{2}$ & $\left(\mathrm{Fe}^{2+}, \mathrm{Mg}\right)_{2}$ & $\mathrm{Fe}^{3+}$ \\
\hline $\begin{array}{l}\text { Diferri-sudoite (Trincal } \\
\text { and Lanari 2016) }\end{array}$ & $(\mathrm{Si})_{2}$ & Si Al & $\square$ & $\left(\mathrm{Fe}^{3+}\right)_{2}$ & $\left(\mathrm{Fe}^{2+}, \mathrm{Mg}\right)_{2}$ & $\mathrm{Al}$ \\
\hline $\begin{array}{l}\text { Triferri-sudoite (This } \\
\text { study) }\end{array}$ & $(\mathrm{Si})_{2}$ & Si Al & $\square$ & $\left(\mathrm{Fe}^{3+}\right)_{2}$ & $\left(\mathrm{Fe}^{2+}, \mathrm{Mg}\right)_{2}$ & $\mathrm{Fe}^{3+}$ \\
\hline $\begin{array}{l}\text { Vacant triferri-amesite } \\
\text { (This study) }\end{array}$ & $(\mathrm{Si})_{2}$ & $(\mathrm{Al})_{2}$ & $\square$ & $\left(\mathrm{Fe}^{3+}\right)_{2}$ & ${ }^{+}\left(\mathrm{Fe}^{2+}, \mathrm{Mg}\right)$ & $\mathrm{Al}$ \\
\hline
\end{tabular}

The speciation of iron is a common issue when calculating structural formulas from electron-microprobe analyses of chlorite, and ferric iron has been emphasized as potentially important for thermobarometric estimates (e.g., Vidal et al. 2005; Inoue et al. 2009; Lanari et al. 2014) but also discarded by some other authors (e.g., Bourdelle and Cathelineau 2015). To model the incorporation of $\mathrm{Fe}^{3+}$ into the chlorite structure, several substitutions and end-members have been proposed. Homovalent exchange of $\mathrm{Al}$ by $\mathrm{Fe}^{3+}\left(\mathrm{Al}=\mathrm{Fe}^{3+}\right)$ has been suggested as a possible mechanism both in octahedral (Vidal et al. 2005; Inoue et al. 2009; Lanari et al. 2014) and tetrahedral position to a smaller extent (Lanson et al. 2012; Muñoz et al. 2013). Trincal and Lanari (2016) highlighted a di-trioctahedral substitution ${ }^{\mathrm{VI}} \square+2{ }^{\mathrm{VI}} \mathrm{Fe}^{3+}=3^{\mathrm{VI}}\left(\mathrm{Mg}, \mathrm{Fe}^{2+}\right)$ that they modeled with a "di-ferri-sudoite" end-member in which $\mathrm{Fe}^{3+}$ replaces $\mathrm{Mg}$ and $\mathrm{Fe}^{2+}$ in M2 and M3 sites (see Table 1). Vidal et al. (2016) suggested another "ferri-sudoite" end-member, with one $\mathrm{Fe}^{3+}$ ion in the M4 site per formula unit (Table 1), following the cation distribution of their previous model (Vidal et al. 2006).

Unfortunately, methods allowing detailed investigations of the cation distribution (such as single-crystal X-ray diffraction) are difficult to set up for ferric chlorite due to frequent zoning, twinning, and crystal deformation; consequently models ground on a limited set of reliable structure refinements. Most studies concur in allocating $\mathrm{Mg}$ and $\mathrm{Fe}^{2+}$ to $\mathrm{M} 1, \mathrm{M} 2$, and $\mathrm{M} 3$ sites (Smyth et al. 1997; Lougear et al. 2000; Aja et al. 2015), and filling the smaller M4 site with Al (Rule and Bailey 1987; Walker and Bish 1992; Nelson and Guggenheim 1993; Welch and Marshall 2001; Zazzi et al. 2006; Aja et al. 2015). Smyth et al. (1997) and Inoue and Kogure (2016) suggest filling the M4 site with $\mathrm{Fe}^{3+}$ when measured, consistent with an $\mathrm{Al}^{3+}=$ $\mathrm{Fe}^{3+}$ exchange.

The presence of octahedral vacancies in chlorite further complicates the estimation of the $\mathrm{Fe}^{3+} / \mathrm{Fe}_{\text {total }}$ ratio, unlike other structural groups in which full site occupancy allows $\mathrm{Fe}^{3+}$ estimation from electron-microprobe data by site-filling methods, as in garnet or chloritoid (e.g., Droop 1987). Estimation of $\mathrm{Fe}^{3+} /$ $\mathrm{Fe}_{\text {total }}$ in chlorite has also been carried out via thermodynamic modeling (e.g., Walshe 1986; Vidal et al. 2006; Lanari et al. 2014; Inoue et al. 2018), however these models are based on a restricted number of analyses with measured iron speciation and little information on cation site distribution. There is a lingering need for measuring and modeling variations in the oxidation state of iron in chlorite, which must be obtained together with major-element composition. Mössbauer spectroscopy (De Grave et al. 1987; Aja and Dyar 2002), electron energy-loss spectroscopy on transmission electron microscope (van Aken and Liebscher 2002; Bourdelle et al. 2013b), photoelectron spectroscopy (Raeburn et al. 1997; Yamashita and Hayes 2008), and EPMA at iron $L \alpha, \beta$ edges (Höfer et al. 1994; Fialin et al. 2001) allow measuring $\mathrm{Fe}^{3+} / \mathrm{Fe}_{\text {total }}$, but all show disadvantages as compared to X-ray absorption near-edge spectroscopy (XANES) for rapid measurement on samples and over scales consistent with scanning electron microscopy and electron microprobe analysis, with limited alteration effects due to the beam - for example electron beams may induce reduction or oxidation with proton loss in hydrous silicates (e.g., Garvie and Craven 1994; Garvie et al. 2004). XANES has been shown 
to be strongly sensitive to both the formal oxidation state and coordination of iron (e.g., Wilke et al. 2001; Newville 2014).

This publication reports on a series of XANES measurements carried out on samples where crystal composition was also measured with scanning electron microscopy and electron microprobe analysis. Iron speciation was measured in oxides and silicates, with emphasis on chlorite, to identify trends in chemical exchanges involving $\mathrm{Fe}^{3+}$. Iron speciation was also mapped in zoned crystals. This effort considerably extends the database for chlorite compositions where iron speciation is known and allows better identification of end-members relevant to ferric chlorite. It is found that the "oxychlorite" component is important even in pristine, apparently unaltered green chlorite. The structure and thermodynamic properties of the ferric end-members remain unknown, however thermodynamic modeling provides first-order constraints on these. Crystal-chemical considerations allow refining the cation site assignment from chlorite electron-microprobe analyses. We propose an alternative algorithm to that of Vidal et al. (2006) for the calculation of end-member activities, which has implications for all compositions and major importance for $\mathrm{Fe}^{3+}$-rich chlorite.

\section{MATERIALS AND METHODS}

Twenty-nine samples of chlorite-bearing rocks from various localities have been measured for their texture, composition, and iron speciation. It was aimed to analyze a wide range of compositions to provide a complete view of solid solutions involving ferric iron. Mineral compositions and sample origin are detailed in Supplemental ${ }^{1}$ Tables S1, S2, and S3. As thin sections were cut perpendicular to the foliation (if any), most chlorite crystals were oriented with $c$-axis in the section plane.

A compilation of analyses from the literature was used for comparison, taken from Trincal and Lanari (2016) but screened with more stringent criteria:

- Sum of "alkalis" $\left(\mathrm{Na}_{2} \mathrm{O}+\mathrm{K}_{2} \mathrm{O}+\mathrm{CaO}\right)$ below $0.5 \mathrm{wt} \%$ to remove analyses possibly contaminated by illite-like material (see e.g., Bourdelle et al. 2013a),

- Sum of oxides between 80 and 91 wt $\%$ (not counting $\mathrm{H}_{2} \mathrm{O}$ ),

- Discarding incorrectly referenced/used analyses (misidentified chlorite, missing analysis in the original paper, missing reference, duplicates).

\section{Scanning electron microscopy and electron microprobe analysis}

Scanning electron microscopy (SEM) was used to complement optical microscopy at ISTeP (Sorbonne Université, Paris) using a Zeiss Supra 55VP apparatus associated to an SSD detector PTG Sahara for imaging and elemental mapping in energy-dispersive spectroscopy mode. Electron probe micro-analyses were then carried out at CAMPARIS (Sorbonne Université, Paris, France) with both Cameca SX-Five and SX-100 instruments. Point measurements were made under classical analytical conditions ( $15 \mathrm{kV}$ acceleration voltage and $10 \mathrm{nA}$ beam current allowing $\sim 2 \mu \mathrm{m}$ beam size, in wavelength-dispersive spectroscopy mode) using diopside (Ca, $\mathrm{Mg}, \mathrm{Si}), \mathrm{MnTiO}_{3}(\mathrm{Mn}, \mathrm{Ti})$, orthoclase $(\mathrm{K}, \mathrm{Al}), \mathrm{Fe}_{2} \mathrm{O}_{3}(\mathrm{Fe})$, albite $(\mathrm{Na})$, and $\mathrm{Cr}_{2} \mathrm{O}_{3}(\mathrm{Cr})$ as standards to measure elements indicated in parentheses. Element maps were obtained with similar conditions but counting time lowered to between 50 and $300 \mathrm{~ms}$. For sessions with analysis of oxygen, alumina $\left(\mathrm{Al}_{2} \mathrm{O}_{3}\right)$ was used as standard, and absorption coefficients were selected from Bastin and Heijligers (1989). Oxygen measurements were subsequently verified with analyzes of periclase $(\mathrm{MgO})$, quartz $\left(\mathrm{SiO}_{2}\right)$, and hematite $\left(\mathrm{Fe}_{2} \mathrm{O}_{3}\right)$, yielding an average relative uncertainty of $1.1 \%$ (here interpreted as trueness) on the measured value for oxygen. This value is lower than the average standard deviation obtained from the electron microprobe on chlorite analyses, yielding a precision generally around $3 \%$ of the measured value (using the manufacturer's software with ZAF correction and the standardization method from this study).

Electron microprobe measurements were combined to iron speciation XANES measurements on the exact same crystals to calculate structural formulas for all minerals. Unless stated otherwise, structural formulas are assumed to be calculated on the basis of $\mathrm{O}_{10}(\mathrm{OH})_{8}$ (i.e., 28 charges) for chlorite, $\mathrm{O}_{5}(\mathrm{OH})_{4}$ for serpentine, and $\mathrm{O}_{10}(\mathrm{OH})_{2}$ for micas.

\section{X-ray absorption near-edge spectroscopy}

$\mathrm{X}$-ray absorption near-edge spectroscopy measurements were carried out for spatially resolved $\mathrm{Fe}^{3+} / \mathrm{Fe}_{\text {total }}$ analysis on both homogeneous and zoned crystals, directly on thin section (i.e., without losing textural information). The oxidation state and coordination number of iron are obtained after spectra processing as detailed below (adapting protocols from White and McKinstry 1966 and Wilke et al. 2001).

Experimental setup. Absorption spectra around the $K$ edge of iron were collected on the ID24 beamline at the European Synchrotron Radiation Facility in Grenoble and on the 13-IDE beamline at APS Chicago. Each beamline was dedicated to XANES in fluorescence detection mode. Setups at Grenoble and Chicago were broadly similar, with the difference that the incident beam was linearly polarized at 13 -IDE and circularly polarized at ID24. Beam spot size was approximately $5 \times 5 \mu \mathrm{m}$. Thin sections were mounted on an iron-free plexiglass holder, fixed on a remotely controlled shelf and positioned perpendicular to the X-ray beam direction to minimize self-absorption effects (Tröger et al. 1992; Pfalzer et al. 1999). Detector sensitivity and distance to the sample were manually adjusted as a function of iron content. For maps, a compromise for coexisting iron-rich and iron-poor minerals was searched with the aim of obtaining the best signal-to-noise ratio for chlorite at the expense of other minerals. Dwell times for spot analyzes and maps were adapted as a function of iron concentration and size of mapped areas. Energy calibration was carried out on hematite crystals and $\mathrm{Fe}$ foils.

The absorption coefficient $\mu$ is defined as $\mu(\mathrm{E})=\log \left(I_{1} / I_{0}\right)$, where $I_{0}$ is the incident beam intensity and $I_{1}$ is the intensity of fluorescence. The absorption coefficient $\mu$ has been measured from 7109 to $7180 \mathrm{eV}$ at ID24 (Fig. 2) and 7062 to $7756 \mathrm{eV}$ at 13-IDE. Spectra were obtained with $0.1 \mathrm{eV}$ resolution around the pre-edge and lower resolutions at lower and higher energies. Two types of detector were used at ID24, and we retained the best spectra in terms of signal-to-noise ratio. Previous studies have shown that linear polarization of incoming photons impacts XANES spectra of anisotropic crystals, and particularly phyllosilicates (e.g., Dyar et al. 2001; Muñoz et al. 2013; Evans et al. 2014), plaguing earlier mapping attempts. Because of linear polarization of the beam at 13-IDE, each crystal has been measured four times, rotating the sample holder by $30^{\circ}$. Because samples were cut perpendicularly to the foliation (along which the long axis of chlorite crystals is generally oriented), this rotation mainly explored the angle between the $c$-axis of chlorite and the beam with the aim of capturing most of the effect of dichroism on the pre-edge of iron without separating crystals and losing textural information. Spectra were subsequently averaged (see Supplemental ${ }^{1}$ Fig. S1 for two examples). Following the analysis of Muñoz et al. (2013), this should average shifting of the pre-edge and limit uncertainties due to linear polarization to about $5 \%$ of the calculated $\mathrm{Fe}^{3+} / \mathrm{Fe}_{\text {total }}$ ratio. Mounting of a quarter-wave plate along the incident beam at ID24 allowed transforming the linearly polarized incident X-ray beam into a transmitted (non-deviated) beam with circular polarization (Giles et al. 1994 ) around the $\mathrm{Fe} K$-edge, making corrections for polarization unnecessary and reliable mapping possible. Because of diffraction effects between the X-ray beam and the quarter-wave crystal, all spectra obtained at ID24 showed a systematic shoulder and trough ("glitch") between 7090 and $7105 \mathrm{eV}$, which has subsequently been considered as part of the background.

The possible effect of beam exposure on iron oxidation state has been tested and dismissed for iron-rich samples via repeated point measurement of the same crystals identified as entirely ferrous or ferric. This is consistent with the study of Fiege et al. (2017) and with results obtained on maps where exposure times were below 30 s per point.

Spectra processing. Figure 2 shows an example of XANES spectrum after normalization and smoothing (using the Savitzky-Golay algorithm). Absorption $\mu$ was normalized using intensities measured in the range $7160-7180 \mathrm{eV}$ to correct for variations of iron content. Several functions were tested to remove the baseline below the pre-edge. This is an important step as the form of the baseline function has been shown to have a critical effect on the area of the pre-edge and on the position of its centroid to a lesser extent (Farges et al. 2004). The pre-edge ranges broadly from 7109 to $7116 \mathrm{eV}$, and these values are affected by iron speciation. It has been found that interpolating the shape of the $K$-edge with piecewise cubic spline interpolation (as used by Wilke et al. 2001; De Andrade et al. 2011) induced bowl shapes under small-intensity pre-edges (i.e., mostly when iron is divalent), overestimating pre-edge areas and at times significantly altering centroid positions. Considering that the first and second energy derivative of the baseline should be positive, and that the $K$-edge of iron should be a pseudo-Voigt function combining a Lorentzian-shaped edge with a Gaussian tail containing the pre-edge stands (see Wilke et al. 2001; Muñoz et al. 2013), we modeled the baseline as purely Gaussianshaped. A Gaussian function was fitted below each pre-edge using values on each side of the pre-edge as constraints, and defining the pre-edge limits such as (1) the 

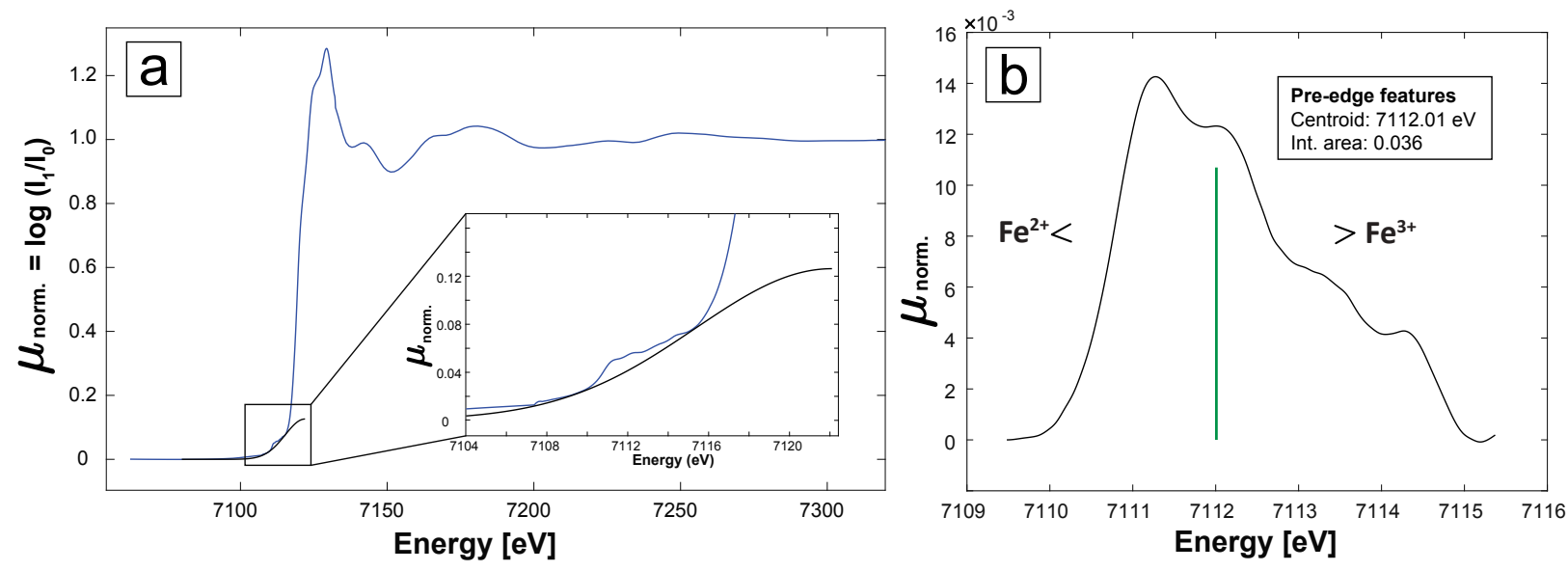

FIGURE 2. Typical XANES spectral features at the Fe $K$ edge for chlorite. (a) Normalized spectrum. The inset shows the pre-edge and the baseline used for extraction of the pre-edge (details in text). (b) Corresponding pre-edge. The vertical line indicates the energy position of the centroid, which increases with increasing $\mathrm{Fe}^{3+} / \mathrm{Fe}_{\text {total }}$ ratio. The area of the pre-edge is sensitive to coordination of $\mathrm{Fe}$, ${ }^{\mathrm{IV}} \mathrm{Fe}$ leading to the larger pre-edge area than ${ }^{\mathrm{VI}} \mathrm{Fe}$.

pre-edge is always contained in the range $7109-7116 \mathrm{eV},(2)$ the pre-edge area is minimum, (3) the baseline has lower intensity than the pre-edge, (4) the baseline has positive first and second derivatives. Due to a large number of analyses carried out here, especially for maps, baseline removal has been automated within an optimization algorithm where points 2 and 3 were equally weighted. Results for all spectra acquired in point mode were manually verified. Some spectra were discarded, in particular spectra containing low signal-to-noise ratio when iron content was too low (detector too far away) and for analyses showing interferences (mostly due to the presence of $\mathrm{Mn}$ and $\mathrm{Cr}$ ).

\section{Propagation of uncertainties}

Structural formulas cumulate uncertainties arising from EPMA and XANES analyses. Analytical propagation of these uncertainties is made difficult first by the normalization procedure (either to a fixed number of charges or to the measured oxygen content) that has the effect of correlating all measurements and their uncertainties, second by the distribution of cations on crystal sites using algorithmic techniques (such as ${ }^{\mathrm{IV}} \mathrm{Al}=4-\mathrm{Si}$ and ${ }^{\mathrm{VI}} \square=6-\Sigma$ octa for chlorite and mica) further correlating uncertainties. Uncertainties have therefore been propagated using Monte-Carlo simulations where a large number of structural formulas (typically 300) were calculated for each EPMA+XANES measurement pair, from as many randomly drawn compositions allowed to vary around each measured value within its uncertainty. For EPMA measurements, uncertainties on measured element weight percentage were taken from the standard deviation obtained from the electron microprobe using the manufacturer's software, which are of the order of $2-3 \%$ of the measured value for major cations ( $>5 \mathrm{wt} \%$ ) and for oxygen where trueness appears better from analysis of standards, to ensure that uncertainties were not under-estimated. For $\mathrm{Fe}^{3+} / \mathrm{Fe}_{\text {total }}$, we used an absolute $15 \%$ uncertainty, as estimated below from the XANES measurements.

In this configuration, after normalization to a fixed number of charges (assuming a fixed anionic basis), uncertainties on structural formulas are in the range $1-3 \%$ of the obtained value for major metals - smaller than point size in Figures 5 and 6 - excluding Fe. Uncertainties on structural formulas are greater with decreasing concentration (e.g., for $\mathrm{Mn}$ ), and for $\mathrm{Fe}^{2+}$ and $\mathrm{Fe}^{3+}$ in Fe-rich minerals where the effect of uncertainties on $\mathrm{Fe}^{3+} / \mathrm{Fe}_{\text {total }}$ is larger. For vacancies, this results in uncertainties typically of the order of 0.02 to $0.1 \mathrm{pfu}$, depending on vacancy content and on Fe content.

For structural formulas normalized to oxygen, uncertainties are larger due to the propagation of the large error on oxygen: $2-4 \%$ of the obtained value for major metals excluding $\mathrm{Fe}$. Again uncertainties on $\mathrm{Fe}^{2+}$ and $\mathrm{Fe}^{3+}$ are often larger than for other metals and increase with $\mathrm{Fe}$ content. Uncertainties on estimated vacancies are much larger than previously, typically in the range $0.2-0.3 \mathrm{pfu}$. For the estimated number of charges (used to deduce proton content), uncertainties are even larger around $0.5 \mathrm{pfu}$. Analyses using this method of normalization have only been carried out on homogeneous minerals, uncertainties have been propagated on median values of several measurements and are reported in corresponding figures and tables.
Comparing both methods of normalization, it is emphasized that neither one increases accuracy over measured relative proportions of metals (e.g., the $\mathrm{Si} / \mathrm{Al}$ ratio and its uncertainty are similar with both methods). However, values estimated after normalization such as vacancy content are dramatically affected. We conclude below that normalizing to measured oxygen results in much more robust trueness for the estimation of vacancies than using a fixed anionic basis, in addition to allowing for verifying deprotonation via charge balance.

\section{RESULTS}

\section{Estimation of iron speciation from XANES spectra}

The energy location of the centroid of each pre-edge and its area for each mineral measured in point mode are provided in Supplemental ${ }^{1}$ Tables S2 to S4.

As shown in Figure 3, these values plotted in the diagram suggested by Wilke et al. (2001) illustrate variations in terms of iron oxidation state and coordination number between ferrous (low energy) and ferric (high energy) minerals and between tetrahedral (large area) and octahedral (low area) coordination of iron. Noting that our data show a spread substantially larger than the end-members defined by Wilke et al. (2001), and this consistently for measurements from both ID-24 (ESRF) and 13-IDE (APS) beamlines, we re-estimated centroid positions for ${ }^{\mathrm{VI}} \mathrm{Fe}^{2+}$ and ${ }^{\mathrm{Vl}} \mathrm{Fe}^{3+}$ end-members using hematite for the ferric end-member at an energy of $7114.2( \pm 0.1) \mathrm{eV}$ and the average value between olivine (from our sample MA15-26B) and chromite (from our sample MA15-31) for the ferrous end-member at an energy of $7111.9( \pm 0.2) \mathrm{eV}$ (Fig. 3a). This is equivalent to using crystals with well-constrained iron speciation as internal standards, to account for differences observed with the study of Wilke et al. (2001). These discrepancies may originate from (1) differences in baseline removal or in standardization of spectra, (2) effects of fluorescence (our study) vs. transmission (Wilke et al. 2001), and (3) evolution of detectors; regardless of the cause, re-estimating end-member values ensures internal consistency to our study. Iron speciation calculations for all minerals were subsequently made on the assumption that pre-edge centroid positions are proportional to the relative amount of ferrous and ferric end-members in the crystal (as described and discussed by 
Bajt et al. 1994 and Wilke et al. 2001). It has been verified from our measurements that an increase in absorption components of the pre-edge that are characteristic of $\mathrm{Fe}^{3+}$ leads to a drift of the centroid energy that can be safely assumed as linear, with regard to the precision on the estimation of the centroid.

End-members for octahedral $\mathrm{Fe}^{2+}$ and $\mathrm{Fe}^{3+}$ differ by $\sim 2.3 \mathrm{eV}$, compared to $\sim 1.4 \mathrm{eV}$ for previous studies (Wilke et al. 2001; Galoisy et al. 2001), as illustrated in Figure 3. Previous studies
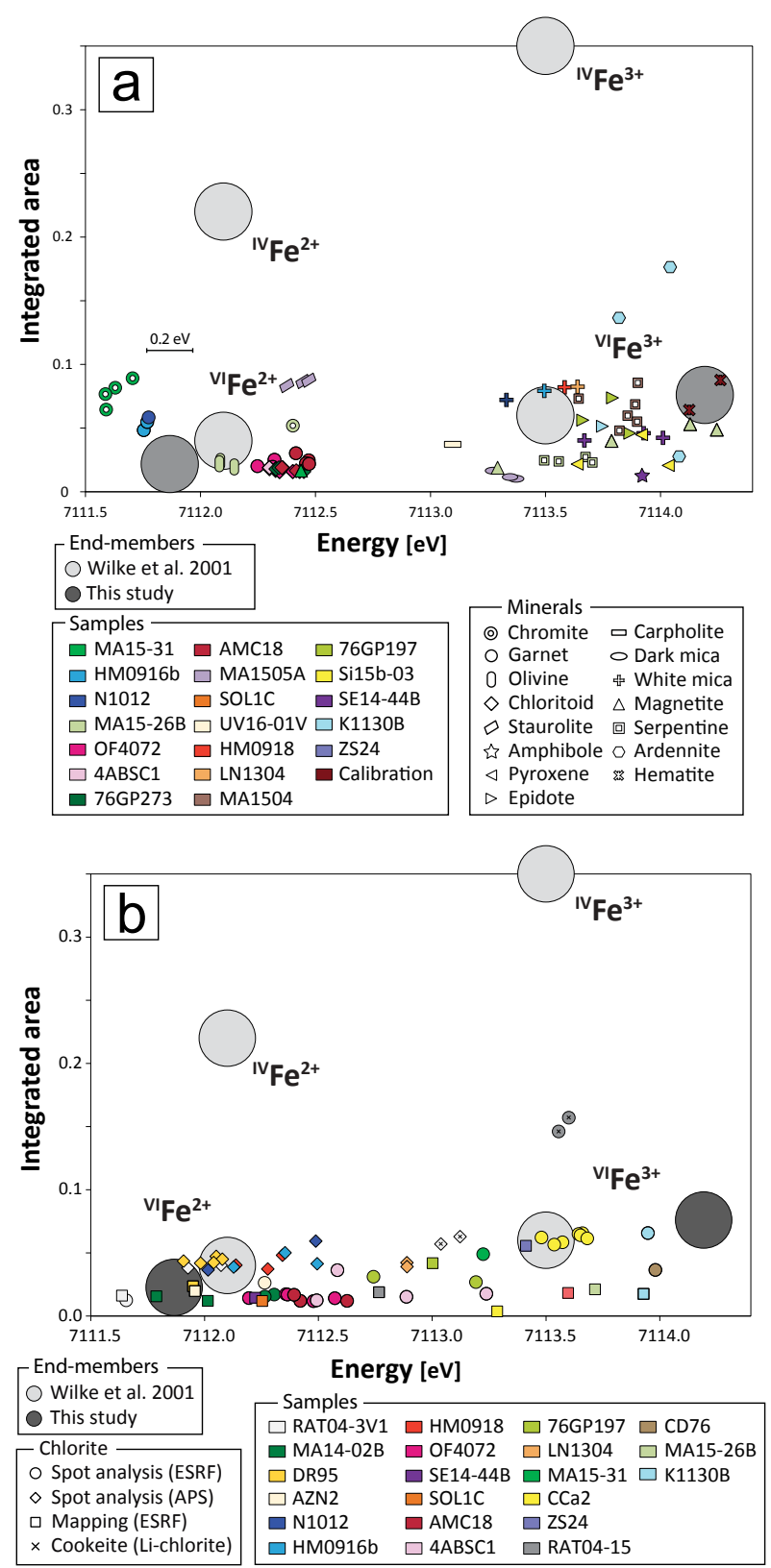

FIGURE 3. XANES results: Integrated area vs. centroid position in energy for (a) a selection of oxides and silicates (standards and minerals associated with chlorite in thin sections); (b) chlorite. Circles show estimated end-member positions for tetrahedral, octahedral, ferrous, and ferric iron, from the study of Wilke et al. (2001, pale circles) and this study (darker circles for octahedral iron). suggest $10 \%$ uncertainty on $\mathrm{Fe}^{3+} / \mathrm{Fe}_{\text {total }}$ with this technique for minerals (Wilke et al. 2005) and 2.4\% for glasses (Fiege et al. 2017), corresponding to uncertainties ranging within 0.1 to 0.3 $\mathrm{eV}$. Analyses carried out on different types of minerals show high reproducibility but considerable scatter, suggesting uncertainties of the order of $0.2 \mathrm{eV}$ on the ferrous end-member. It follows that an absolute uncertainty of $15 \%$ on each $\mathrm{Fe}^{3+} / \mathrm{Fe}_{\text {total }}$ estimate seems reasonable for our data set.

\section{Speciation and coordination of iron}

Chlorite crystals from this study cover almost the entire range of $\mathrm{Fe}^{3+} / \mathrm{Fe}_{\text {total }}$ ratio, from 0 to $95 \%$ (Supplemental ${ }^{1}$ Table S1, Fig. 3). The garnet and chloritoid crystals analyzed in point mode are homogeneous and bear almost exclusively ferrous iron. In all serpentine crystals, iron is essentially ferric. No crystal in our collection contains purely tetrahedral iron. Staurolite shows large pre-edge area values, consistent with the presence of both tetrahedral and octahedral iron in its structure (e.g., Smith 1968; Dyar et al. 1991a; Hawthorne et al. 1993). The Mn-Alarsenatosilicate ardennite also contains a significant proportion of tetrahedral $\mathrm{Fe}^{3+}\left(\sim 25 \%\right.$ of the $\sim 0.5 \mathrm{wt} \% \mathrm{Fe}_{2} \mathrm{O}_{3 \text { (total) }}$ reported by Altherr et al. 2017), which is a new feature. Tetrahedral iron was found making as much as $\sim 25 \%$ of total iron in cookeite [Li-rich chlorite with $<1 \mathrm{wt} \% \mathrm{Fe}_{2} \mathrm{O}_{3 \text { (total) }}$, ideally $\left.\mathrm{LiAl}_{4} \mathrm{Si}_{3} \mathrm{AlO}_{10}(\mathrm{OH})_{8}\right]$, but was below the detection limit for all other chlorite crystals.

\section{Areal variations: $\mathrm{Fe}^{3+} / \mathrm{Fe}_{\text {total }}$ mapping in chlorite-bearing assemblages}

One of the goals of this study was to test the feasibility of XANES mapping of sheet-silicates and its suitability to petrological purposes. Out of seven maps acquired, Figure 4 shows results obtained on a rodingite sample bearing andraditic hydrogarnet, pyrite, and two generations of chlorite (10-14 wt $\%$ $\mathrm{FeO}_{\text {total }}$ in the early one, $4-8 \mathrm{wt} \% \mathrm{FeO}_{\text {total }}$ in the late, matrixforming one). XANES measurements appear clustered (Figs. $4 b, 4 c$, and 4d) and faithfully render the two chlorite generations (cf. EPMA data in Fig. 4a), regardless of the (variable) crystal orientation. The early, Fe-rich generation is less oxidized $\left(\mathrm{Fe}^{3+} /\right.$ $\mathrm{Fe}_{\text {total }}$ in the range $\left.0.2-0.4\right)$ than the late one $\left(\mathrm{Fe}^{3+} / \mathrm{Fe}_{\text {total }}\right.$ in the range $0.35-0.7$; Figs. $4 \mathrm{c}$ and $4 \mathrm{~d})$. Yet, in spite of the significant increase in the $\mathrm{Fe}^{3+} / \mathrm{Fe}_{\text {total }}$ ratio between the two generations, their $\mathrm{Fe}^{3+}$ content remains similar, in the range $0.25-0.35 \mathrm{pfu}$, as seen in structural formulas given in Table 2 for the areas labeled 1 to 4 on Figure 4 . In this case, the $\mathrm{Fe}^{2+}-\mathrm{Mg}$ exchange explains most of the chemical variability, $X_{\mathrm{Mg}}=\mathrm{Mg} /\left(\mathrm{Mg}+\mathrm{Fe}^{2+}\right)$ passing from 0.81 to 0.97 .

Garnet in this sample is $\mathrm{Fe}^{3+}$-rich, and its boundary is hardly identified in the $\mathrm{Fe}^{3+} / \mathrm{Fe}_{\text {total }}$ map (Fig. 4c), suggesting possible contamination of nearby chlorite analyses by fluorescence. However, this effect can be ruled out as both the $\mathrm{Fe}_{\text {total }}$ map measured by XANES (Fig. 4b) and the $\mathrm{Fe}_{\text {total }}$ vs. $\mathrm{Fe}^{3+} / \mathrm{Fe}_{\text {total }}$ plot (Fig. 4d) show distinct clusters for garnet and chlorite. The $\mathrm{Fe}_{\text {total }}$ map measured by XANES compares very favorably with the EPMA Fe map (Figs. 4a vs. 4b), with similarly sharper boundaries for garnet-chlorite grain boundaries than between chlorite generations. Analyses showing contamination appear restricted to the few pixels straddling grain boundaries. This reliability opens good prospects for further petrological applications. 


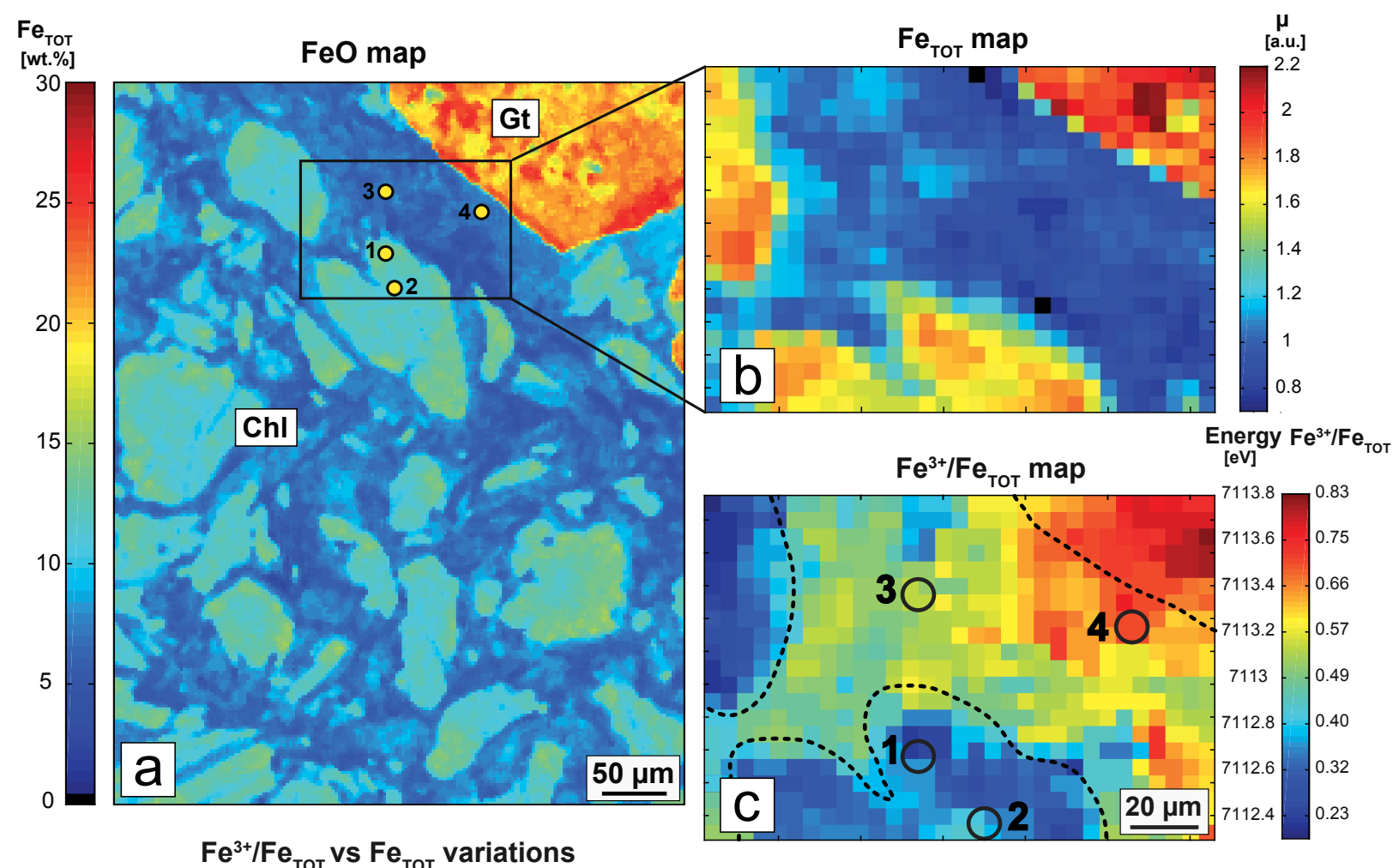

FIGURE 4. XANES and EPMA mapping of a rodingite sample (So15-27, with chlorite $\mathrm{Chl}, \mathrm{Fe}^{3+}$-rich hydrogarnet $\mathrm{Gt}$, and pyrite not appearing here) illustrating two generations of chlorite with different $X_{\mathrm{Mg}}$. (a) FeO map as obtained from EPMA $(400 \times 600 \mu \mathrm{m})$. The inset shows the area measured with XANES. (b and $\mathbf{c})$ XANES maps of total $\mathrm{Fe}\left(\mathrm{Fe}_{\text {Тот, }}\right.$, arbitrary units showing height of spectra after $K$ edge before normalization) and $\mathrm{Fe}^{3+} / \mathrm{Fe}_{\text {тот. }}$ (d) Correlation between $\mathrm{Fe}_{\text {тот }}$ in the XANES map (lower $\mathrm{x}$ axis) indexed over EPMA measurements (upper $\mathrm{x}$ axis) and iron oxidation state expressed in terms of centroid position (y axis, left) and $\mathrm{Fe}^{3+} / \mathrm{Fe}_{\text {тот }}$ (y axis, right). Garnet analyses are shown in red, chlorite in green. Four points selected for calculation of structural formulas (Table 2) are shown in $\mathbf{a}, \mathbf{c}$, and $\mathbf{d}$.

TABLE 2. Chlorite composition (from EMPA and XANES data) in areas 1 to 4 in the maps of Figure 4 (sample So15-27)

\begin{tabular}{|c|c|c|c|c|c|c|c|c|c|c|}
\hline \multirow[t]{2}{*}{ Area } & \multicolumn{3}{|c|}{ wt $\%$} & \multicolumn{6}{|c|}{ apfu $\left[\mathrm{O}_{10}(\mathrm{OH})_{8}\right.$ basis] } & \multirow[t]{2}{*}{$\mathrm{Fe}^{3+} / \mathrm{Fe}_{\text {Tota }}$} \\
\hline & $\mathrm{SiO}_{2} \quad \mathrm{Al}_{2} \mathrm{O}_{3}$ & $\mathrm{FeO}_{\text {Total }}$ & $\mathrm{MgO}$ & $\mathrm{Si}$ & $\mathrm{Al}$ & $\mathrm{Fe}^{2+}$ & $\mathrm{Fe}^{3+}$ & $\mathrm{Mg}$ & $\square$ & \\
\hline 1 & 33.4114 .69 & 13.42 & 25.21 & 3.27 & 1.70 & 0.85 & 0.25 & 3.68 & 0.25 & 0.23 \\
\hline 2 & 33.7414 .60 & 11.09 & 26.50 & 3.28 & 1.67 & 0.54 & 0.36 & 3.84 & 0.30 & 0.40 \\
\hline 3 & 35.6114 .84 & 7.07 & 31.57 & 3.28 & 1.61 & 0.26 & 0.29 & 4.33 & 0.23 & 0.53 \\
\hline 4 & 32.1313 .69 & 5.88 & 28.93 & 3.25 & 1.63 & 0.15 & 0.35 & 4.37 & 0.25 & 0.70 \\
\hline
\end{tabular}

tending toward the hypothetical Al-free end-member (Holland et al. 1998; Inoue et al. 2009; Bourdelle et al. 2013a), which has a serpentine composition but a chlorite structure (14 $\AA$ ). A more remarkable feature of Figure $5 \mathrm{a}$ is that a number of chlorite analyses plot outside but on the opposite side of the classical clinochlore-amesite range, i.e., on the $\mathrm{R}^{3+}$-rich side. These analyses are mostly those of crystals containing more than $0.1 \mathrm{Fe}^{3+}$ pfu (Figs. 5b and 5c). In two samples (4ABSC1 and CD76), chlorite incorporates as much as 1.0 to $2.8 \mathrm{Fe}^{3+}$ pfu (Supplemental ${ }^{1}$ Table S1 and Figs. 5b and 5c).

The analyzed micas contain from 0.06 to $0.28 \mathrm{Fe}^{3+}$ pfu 
and have $\mathrm{Fe}^{3+} / \mathrm{Fe}_{\text {total }}$ values between 0.62 and 0.92 . Serpentine analyses show $\mathrm{Fe}^{3+}$ contents ranging from 0.07 to 0.14 pfu and $\mathrm{Fe}^{3+} / \mathrm{Fe}_{\text {total }}$ ratios between 0.75 and 0.87 .

In this data set, chlorite, therefore, shows by far the highest $\mathrm{Fe}^{3+}$ contents and the largest variations in $\mathrm{Fe}^{3+} / \mathrm{Fe}_{\text {total }}$ ratio, which begs the question of the involved substitutions.

\section{Substitutions and possible ferric end-members for chlorite}

Chlorite compositions are shown in Figures 5 and 6 together with literature values.

Low-Fe chlorite: Al-Fe ${ }^{3+}$ exchange. The first group of chlorite analyses was best identified through high $\mathrm{Fe}^{3+} / \mathrm{Fe}_{\text {total }}$, low iron content (high $X_{\mathrm{Mg}}$, low $\mathrm{Fe}_{\text {total }}$ ) and low vacancy number (Figs. 5b, 5c, 6a, and 6b). Such compositions highlight the need for at least one tri-trioctahedral, magnesian, Al-exchanged ferric end-member (Fig. 6a) such as "ferri-clinochlore" and/or "Mg-ferri-amesite" (the latter being more likely according to Fig. 6b). These end-members remain fictive as none of them is dominant in these samples, but they are needed to encompass the compositional field of ferric chlorites (Fig. 5b).
High-Fe chlorite: Vacancy creation or "oxychlorite"? The second group of compositions stands out by their high $\mathrm{Fe}^{3+}$ contents, hence high $\mathrm{Fe}_{\text {total }}$. A striking feature of $\mathrm{Fe}^{3+}$ incorporation is the increasing octahedral vacancy with increasing $\mathrm{Fe}^{3+}$ content (as shown in Fig. 5b). This trend has already been identified by Trincal and Lanari (2016; also Billault et al. 2002, in Fe-rich sudoite) and explained by coupled substitution of three divalent cations by two $\mathrm{Fe}^{3+}$ cations, similarly to the di-trioctahedral substitution: ${ }^{\mathrm{VI}} \square+2{ }^{\mathrm{VI}} \mathrm{Fe}^{3+}=3{ }^{\mathrm{VI}}\left(\mathrm{Mg}, \mathrm{Fe}^{2+}\right)$. This exchange reaction must be completed by some $\mathrm{Al}=\mathrm{Fe}^{3+}$ substitution, first to account for analyses with $\mathrm{Fe}^{3+}>2$ pfu (Figs. $5 \mathrm{~b}$ and $6 \mathrm{~b}$ ), then to explain deviation from a straight line in Figure 5b, and finally to explain $\mathrm{Fe}^{3+}$ incorporation in trioctahedral crystals (i.e., without vacancy, Fig. 6a) forming the first group addressed above. Both substitutions may act concomitantly (Fig. 5c), along the vacancy-creating substitution ${ }^{\mathrm{V}} \mathrm{\square}+2{ }^{\mathrm{VI}} \mathrm{R}^{3+}=3^{\mathrm{VI}}\left(\mathrm{Mg}, \mathrm{Fe}^{2+}\right)$ where $\mathrm{R}^{3+}$ may be $\mathrm{Al}$ or $\mathrm{Fe}^{3+}$. In other words, incorporation of trivalent cations above 2 apfu appears controlled by the di-trioctahedral substitution (Fig. 5c) with $\mathrm{Al}$ and $\mathrm{Fe}^{3+}$ exchanging for one another (Fig. 6a).

Vacancy creation during $\mathrm{Fe}^{3+}$ incorporation through the

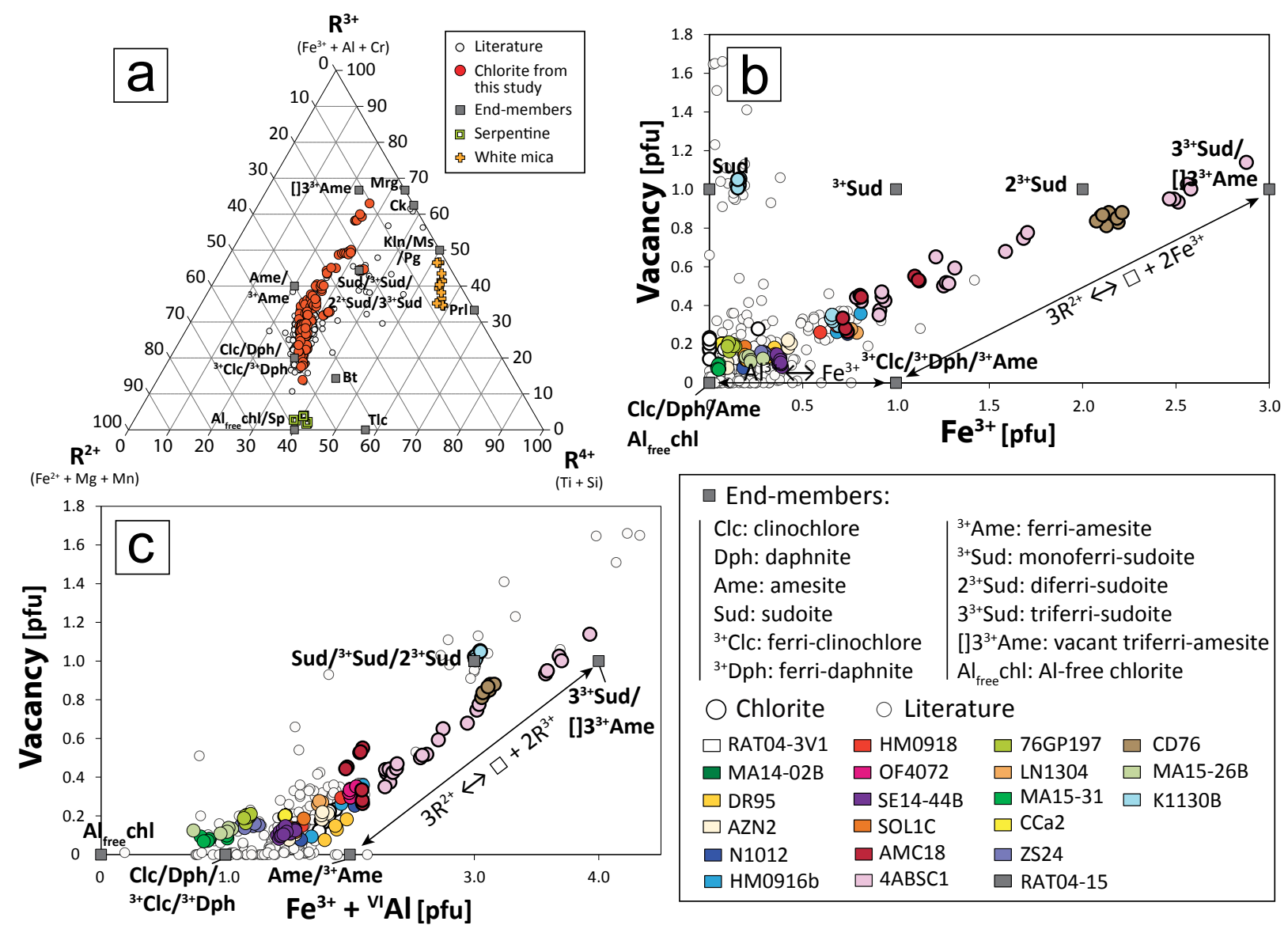

FigURE 5. Chlorite compositions from this study (color symbols) and from the literature (open symbols) together with possible chlorite end-members as defined in Table 1 (continued in Fig. 6). (a) Composition of chlorite, serpentine, and micas in a $\mathrm{R}^{2+}-\mathrm{R}^{3+}-\mathrm{R}^{4+}$ diagram, together with various phyllosilicate end-members. $\mathrm{Bt}=$ biotite $\mathrm{Ck}=$ cookeite; $\mathrm{Kln}=$ kaolinite $\mathrm{Mrg}=$ margarite; $\mathrm{Ms}=\operatorname{muscovite} ; \mathrm{Pg}=$ paragonite; $\mathrm{Prl}=$ pyrophyllite; $\mathrm{Sp}=$ serpentine; $\mathrm{Tlc}=$ talc. $(\mathbf{b}$ and $\mathbf{c})$ Chlorite vacancy content as a function of $\mathrm{Fe}^{3+}$ content $(\mathbf{b})$, and of the sum of ${ }^{\mathrm{VI}} \mathrm{Al}$ and $\mathrm{Fe}{ }^{3+}(\mathbf{c})$. The trend defined by the di-trioctahedral substitution ${ }^{\mathrm{VI}} \square+2{ }^{\mathrm{VI}} \mathrm{R}^{3+}=3{ }^{\mathrm{VI}}\left(\mathrm{Mg}, \mathrm{Fe}^{2+}\right)$ is shown in $\mathbf{b}$ and $\mathbf{c}$. Bold symbols in $\mathbf{b}$ show crystals selected for normalization to measured oxygen content (see Fig. 7). 

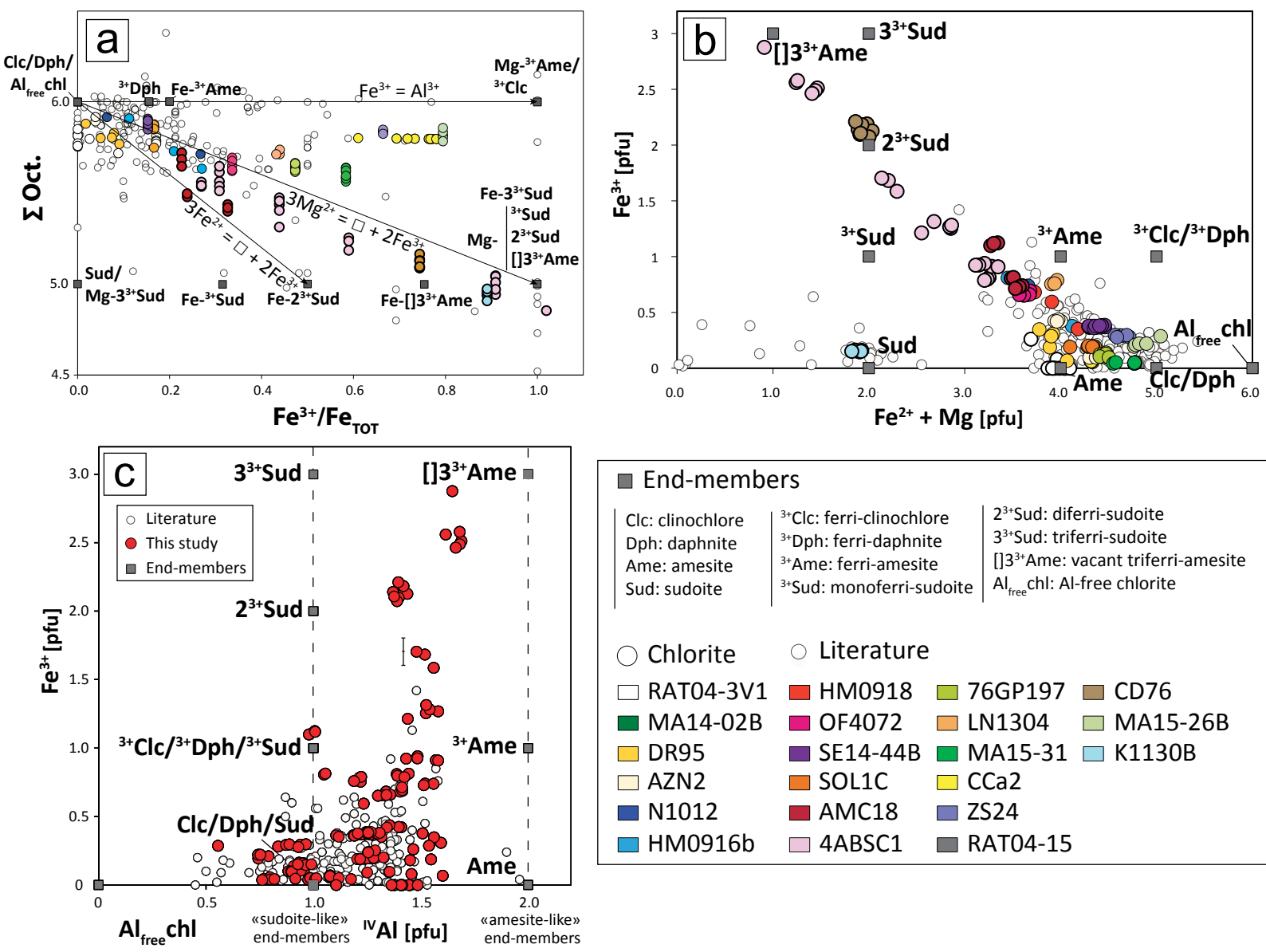

FIGURE 6. The composition of chlorite from this study (color symbols) and from the literature (open symbols) together with possible chlorite end-members (continued from Fig. 5). (a) Octahedral sum as a function of the oxidation state of iron, with trends defined by $\mathrm{Al}-\mathrm{Fe}^{3+}$ exchange and di-trioctahedral exchanges shown for $\mathrm{Mg}$ and $\mathrm{Fe}^{2+}$. (b) Correlation between $\mathrm{Fe}^{3+}$ and the sum of $\mathrm{Fe}^{2+}$ and $\mathrm{Mg}$. (c) $\mathrm{Fe}^{3+}$ content vs. tetrahedral $\mathrm{Al}$.

above equation may be modeled with several di-trioctahedral end-members, either trisilicic (i.e., $\mathrm{Si} /{ }^{/ v} \mathrm{Al}=3$, of the sudoite type) or disilicic (i.e., $\mathrm{Si} /{ }^{\mathrm{IV}} \mathrm{Al}=1$, of the "vacant-amesite" type). Both types allow for several end-members with various $\mathrm{Fe}^{3+}$ content, such as "ferrisudoite"-type end-members with formulas $\square\left(\mathrm{Mg}, \mathrm{Fe}^{2+}\right)_{2} \mathrm{Al}_{3-\mathrm{x}} \mathrm{Fe}_{\mathrm{x}}^{3+}\left(\mathrm{Si}_{3} \mathrm{Al}\right) \mathrm{O}_{10}(\mathrm{OH})_{8}$ where $\mathrm{x}$ may vary between 1 and 3 (Table 1). As seen in Figure 6a, analyses tend toward an Mg-rich end-member (of sudoite or amesite type) with some Fe entirely in trivalent state, rather than a $\mathrm{Fe}_{\text {total }}$-rich end-member with mixed valence (in which Fe would be found in both ferrous and ferric state). Figure $6 \mathrm{c}$ shows that $\mathrm{Fe}^{3+}$-rich analyses fall in the range $1.4-1.6{ }^{\mathrm{V}} \mathrm{Al} \mathrm{pfu}$, requiring both disilicic and trisilicic end-members for their formulation.

However, the plausibility of such ferric end-members with dioctahedral character rests heavily on proper estimation of the amount of vacancy, which is fraught with three main sources of error: (1) incorrect definition of the chemical system and neglect of minor elements, (2) cumulating analytical uncertainties, and (3) high sensitivity to the formula normalization basis. The first source of error (overlooked elements) may be ignored when careful EDS measurements lead to estimated vacancy content above $0.5 \mathrm{pfu}$ unless lithium is present. The second source of error (cumulating analytical uncertainties) could not explain either such large vacancy contents if EPMA measurements were carefully carried out. The third source of error is the important one, as shown below, due to possible deprotonation in hydrous silicates, as advocated by Dyar et al. (1993). For chlorite, the standard assumption of a fixed $\mathrm{O}_{10}(\mathrm{OH})_{8}$ anionic basis in the structural formula may lead to a severe bias in vacancy estimation through normalization to 28 negative charges $Q_{\text {norm }}[18$ $\mathrm{O}^{2-}$ and $8 \mathrm{H}^{+}$make $Q_{\text {norm }}=18 \times(-2)+8=-28$, corresponding to 14 oxygen anhydrous basis]. Indeed, in the case one proton is lost by clinochlore $\mathrm{Mg}_{5} \mathrm{Al}_{2} \mathrm{Si}_{3} \mathrm{O}_{10}(\mathrm{OH})_{8}$ along an exchange vector like $\mathrm{Mg}^{2+}+\mathrm{H}^{+}=\mathrm{Al}^{3+}$ (Dyar et al. 1993), the structural formula becomes $\mathrm{Mg}_{4} \mathrm{Al}_{3} \mathrm{Si}_{3}$ with anionic composition $\mathrm{O}_{11}(\mathrm{OH})_{7}$ and 29 negative charges $\left[18 \mathrm{O}^{2-}\right.$ and $7 \mathrm{H}^{+}$make $Q_{\text {norm }}=18 \times(-2)$ $+7=-29]$; if proton loss is ignored, the EPMA analysis of this $\mathrm{Mg}_{4} \mathrm{Al}_{3} \mathrm{Si}_{3} \mathrm{O}_{11}(\mathrm{OH})_{7}$ tri-trioctahedral deprotonated chlorite will be expressed as $\square_{0.35} \mathrm{Mg}_{3.85} \mathrm{Al}_{2.90} \mathrm{Si}_{2.90} \mathrm{O}_{10}(\mathrm{OH})_{8}$. In other words, the loss of one proton will lead to the artificial estimation of 0.35 vacancy - and the trend identified between vacancy and $\mathrm{Fe}^{3+}$ content (in Fig. 5b and earlier studies) may simply be an artifact resulting from normalization to a fixed number of charges.

Therefore, the key datum to identify the effective substitution(s) 
responsible for $\mathrm{Fe}^{3+}$ incorporation is the actual number of $\mathrm{OH}$ groups pfu-which is at hand if one combines XANES data and EPMA including oxygen. Since the total number of oxygen atoms pfu remains unaffected, the actual oxygen content (measured by EPMA) can be used to calculate the formula on the basis of 18 oxygen atoms and, with the $\mathrm{Fe}^{3+} / \mathrm{Fe}_{\text {total }}$ ratio from XANES data as input, the number of $\mathrm{H}^{+}$pfu is then obtained by charge balance. This calculation admittedly cumulates analytical uncertainties and is sensitive to small deviations in the measured oxygen content (due to, e.g., surface roughness, matrix effects or contamination by minerals with lower $\mathrm{OH}$ content). To test the validity of this new approach, oxygen was measured by EPMA (see Materials and methods) on five chlorite-bearing samples covering the compositional range and trends identified in Figures 5 and $6(0 \leq$ $\mathrm{Fe}^{3+} / \mathrm{Fe}_{\text {total }} \leq 0.9 ; 0 \leq \mathrm{Fe}^{3+} \leq 2.2 \mathrm{pfu} ; 0<\mathrm{Fe}^{2+} \leq 3.2 \mathrm{pfu} ; 0.2 \leq \square \leq$ $1.1 \mathrm{pfu})$ and including sudoite, known to be di-trioctahedral. The results are reported in Figure 7 and, except for the zoned, very heterogeneous sample 4ABSC1, median values given in Table 3.

The spread in $\mathrm{H}^{+}$and vacancy values for each homogeneous sample or subsample in Figures $7 \mathrm{~b}$ and $7 \mathrm{c}$ is a direct reflection of the dependency of the estimation on oxygen analysis, which
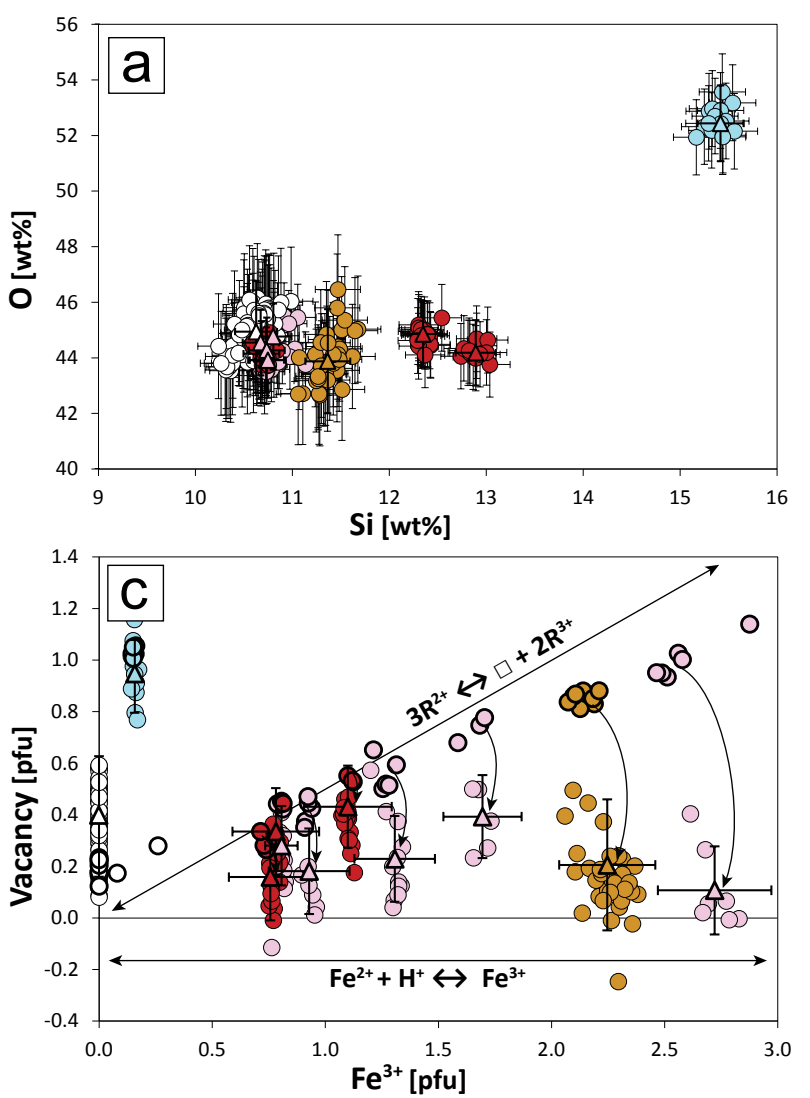

is less precise than for metals (Fig. 7a). Mean vacancy numbers are in the range of 0.2 to $0.4 \mathrm{pfu}$, except for the sudoite sample (K1130B), gratifyingly close to $1 \mathrm{pfu}$, thereby lending credence to the oxygen analysis procedure. Mean values of $\mathrm{H}^{+}$are in the plausible range 6.0-8.7 pfu for homogeneous samples or subsamples (Table 3), hinting at possible over-estimation of $\mathrm{H}^{+}$by about 0.5 proton, especially for the RAT04-3v1 sample, although half a proton pfu is the general uncertainty over estimated $\mathrm{H}^{+}$ content. For this sample, underestimation of $\mathrm{Fe}^{3+} / \mathrm{Fe}_{\text {total }}$ (by $\sim 25 \%$ when neglecting all other sources of uncertainties) would be necessary to explain solely this excessive proton estimate. Yet, the whole procedure is sufficiently precise to establish the following solid results in our data set:

- The iron-rich chlorites are close to trioctahedral $(\square<0.4$ pfu), regardless of iron oxidation state (cf. CD76 and RAT043v1; Fig. 7c, Table 3);

- Deprotonation is an effective process, definitely linked to increasing $\mathrm{Fe}^{3+}$ content (Fig. 7b). It reaches and might exceed a loss of $2 \mathrm{H}^{+}$pfu.

These results have important consequences for incorporation mechanisms of $\mathrm{Fe}^{3+}$. The relation found between the number of
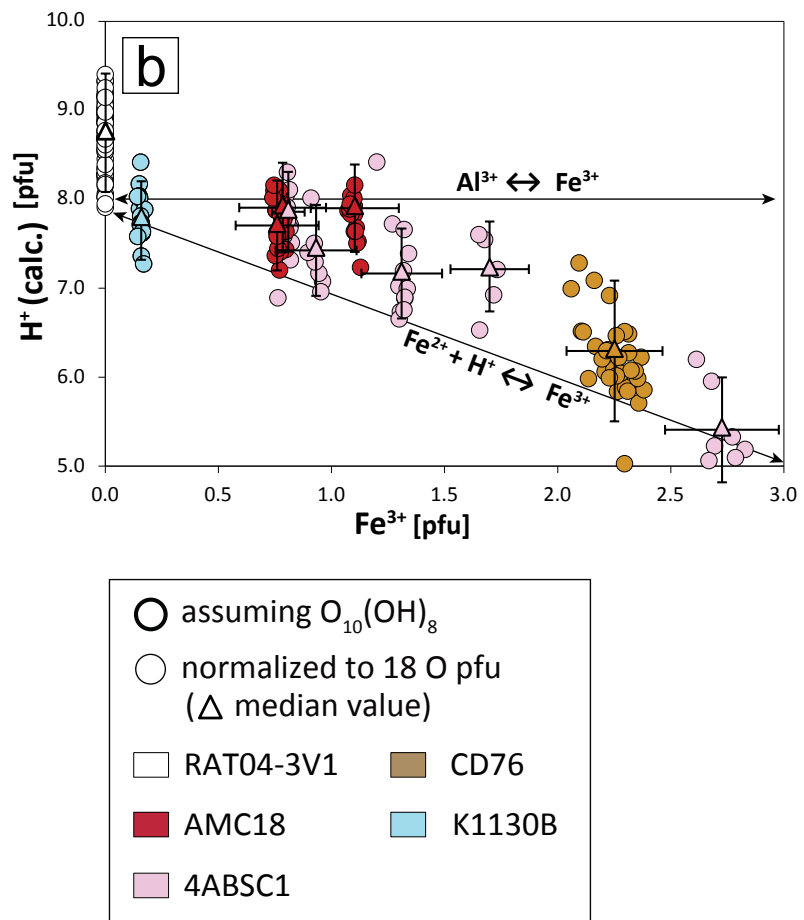

FIGURE 7. The composition of chlorite in five samples measured with EPMA, including oxygen, which is used for normalization to 18 oxygen atoms. Iron oxidation is set with XANES measurements. (a) Oxygen content as a function of $\mathrm{Si}$ as measured with EPMA. (b) The number of protons obtained by charge balance (as explained in the text). The exchange vector $\mathrm{Fe}^{2+}+\mathrm{H}^{+}=\mathrm{Fe}^{3+}$ is shown together with the $\mathrm{Fe}^{3+}=\mathrm{Al}$ exchange. $(\mathbf{c})$ Vacancy amount obtained after normalization to oxygen, compared to that obtained by normalization to 28 charges $\left(\left[i . e\right.\right.$., $\mathrm{O}_{10}(\mathrm{OH})_{8}$ anionic basis; bold symbols, as in Fig. 5b]. Arrows highlight the decrease in estimated vacancy content. Note that (1) the sudoite sample (K1130B) is unaffected, and (2) for each sample, scatter increases with normalization to oxygen, due to sensitivity to small variations in oxygen measurement. Uncertainties from EPMA and XANES measurements are propagated on median values for each compositional group as described in the text. 
protons and $\mathrm{Fe}^{3+}$ content shows that $\mathrm{R}^{2+}+\mathrm{H}^{+}=\mathrm{Fe}^{3+}$ is an effective net exchange in chlorite, as suggested by Dyar et al. (1993) and observed in other hydrous silicates. Most importantly, the trend defined by the $3 \mathrm{R}^{2+}=\square+2 \mathrm{Fe}^{3+}$ exchange vector (i.e., the vacancy-creating trend) in Figures $5 \mathrm{~b}, 5 \mathrm{c}$, and 6 a essentially disappears from our data set after normalization to oxygen (cf. bold and non-bold symbols in Fig. 7c). This casts doubt on conclusions made in the literature from data showing an identical trend of increasing vacancy with $\mathrm{Fe}^{3+}$ content, because vacancy may just be the result of normalization to a fixed number of charges, the most common practice with EPMA data.

In any case, our results do not support the existence of ditrioctahedral ferric end-members as recently proposed for common chlorites (Vidal et al. 2016; Trincal and Lanari 2016) - even if at least one is needed to account for $\mathrm{Fe}^{3+}$-rich sudoite (Billault et al. 2002). Rather, the high contents of $\mathrm{Fe}^{3+}$ found in our samples are mostly linked to proton loss, with a potential contribution of $\mathrm{Al}^{3+}-\mathrm{Fe}^{3+}$ exchange. There is no indication of other substitution linked to proton loss such as $\mathrm{R}^{2+}+\mathrm{H}^{+}=\mathrm{Al}^{3+}$.

\section{DISCUSSION}

\section{Incorporation of $\mathrm{Fe}^{3+}$}

Cation distribution in $\mathrm{Fe}^{3+}$-rich chlorite. Ferric iron exchanging with $\mathrm{Al}$, either as homovalent substitution or through di-trioctahedral $\left.{ }^{\mathrm{VI}} \square+2{ }^{\mathrm{VI}} \mathrm{R}^{3+}=3{ }^{\mathrm{VI}}\left(\mathrm{Mg}, \mathrm{Fe}^{2+}\right)\right]$ or Tschermaklike $\left(\mathrm{Si}^{4+}+{ }^{\mathrm{VI}} \mathrm{R}^{2+}={ }^{\mathrm{IV}} \mathrm{Al}^{3+}+{ }^{\mathrm{VI}} \mathrm{R}^{3+}\right)$ substitutions, leads to the possible existence of many ferric end-members. In the absence of structure refinements for these ferric end-members, empirically derived methods of estimation of the enthalpy of formation can be used to test for possible cation distributions after exchange reactions described above, which involve several crystal sites. The polyhedral oxide summation methods of Chermak and Rimstidt (1989) and van Hinsberg et al. (2005) were used and extended to protonated $\mathrm{Fe}^{3+}$-centered octahedra (Fig. 8) to estimate the formation enthalpy of such compounds. A fundamental observation in Figure 8 is that for all components, the formation enthalpy steadily decreases from anhydrous octahedral sites (not found in chlorite) to mica-like $\mathrm{OH}$-bearing octahedra (M1 and M2 sites of chlorite) to octahedra where all oxygen atoms are protonated (M3 and M4 sites of chlorite), which have the most negative enthalpy of formation. This implies that vacancy-rich compounds with chlorite structure are thermodynamically favored when the M3 and M4 sites (hydroxide interlayer) are fully occupied and vacancies are located in the M1 or M2 sites (TOT layer). Depending on the composition, the gain in energy is between 5 and 20 times the uncertainties given by the two methods, which therefore is regarded as robust proof. The same method applied for the enthalpy of formation of sudoite, $\square \mathrm{Mg}_{2} \mathrm{Al}_{3}\left(\mathrm{Si}_{3} \mathrm{Al}\right) \mathrm{O}_{10}(\mathrm{OH})_{8}$, yields $-8647 \pm 80 \mathrm{~kJ} / \mathrm{mol}$ or $-8526 \pm$ $73 \mathrm{~kJ} / \mathrm{mol}$ with van Hinsberg et al. (2005) values, depending on whether the vacancy is located in the TOT octahedral sheet or in the interlayer hydroxide sheet, respectively. These bulk values are not significantly different, but their difference $(121 \pm 7 \mathrm{~kJ} / \mathrm{mol})$ is obtained with a much smaller uncertainty and confirms the preferred occurrence of vacancies in the octahedral sheet of the TOT layer. This analysis is consistent with the abundance of natural examples of di-trioctahedral chlorite (with vacancies in
TABLE 3. Chemical analyses (averaged) of chlorite based on EPMA (O measured) and XANES data

\begin{tabular}{|c|c|c|c|c|c|c|c|c|c|}
\hline \multirow[t]{2}{*}{ Sample } & \multicolumn{9}{|c|}{ Atom wt $\%$} \\
\hline & $\mathrm{Si}$ & $\mathrm{Ti}$ & $\mathrm{Al}$ & $\mathrm{Fe}$ & $\mathrm{Mn}$ & $\mathrm{Mg}$ & Alk. $^{a}$ & 0 & Total \\
\hline Rat04 & 10.60 & 0.01 & 13.41 & 25.86 & 0.07 & 3.87 & 0.13 & 44.88 & 98.83 \\
\hline CD76 & 11.36 & 0.00 & 10.51 & 25.82 & 0.60 & 5.32 & 0.53 & 43.94 & 98.10 \\
\hline \multirow[t]{3}{*}{ AMC18 } & 12.35 & 0.03 & 9.32 & 28.93 & 0.18 & 4.05 & 0.94 & 44.80 & 100.92 \\
\hline & 12.18 & 0.02 & 9.44 & 28.58 & 0.16 & 4.50 & 0.54 & 44.20 & 99.87 \\
\hline & 12.54 & 0.01 & 8.95 & 29.04 & 0.17 & 4.20 & 0.87 & 44.55 & 100.62 \\
\hline K1130B & 15.37 & 0.02 & 19.31 & 1.79 & 0.37 & 8.33 & 0.20 & 52.53 & $98.83^{\mathrm{c}}$ \\
\hline
\end{tabular}

(Table extends on next page)

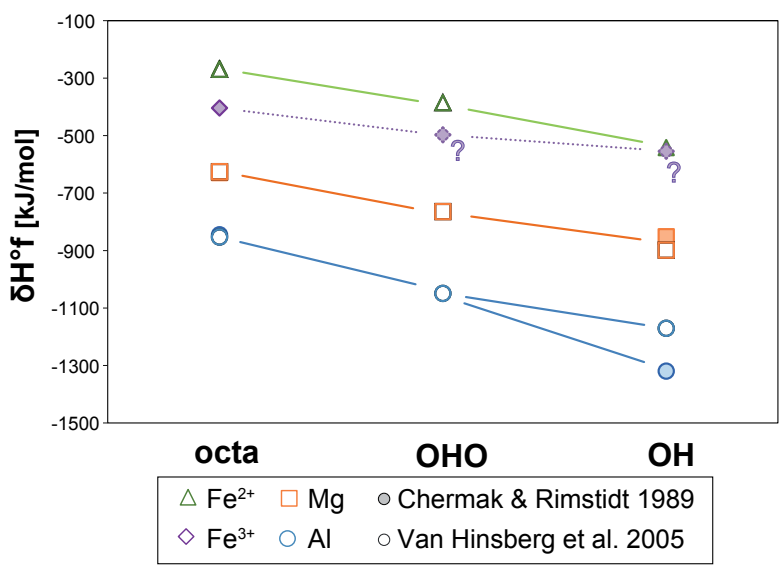

FIGURE 8. Estimated contribution to the enthalpy of formation for oxide polyhedral components as a function of their protonation. "octa" stands for anhydrous octahedra (e.g., Mg in olivine), "OHO" for partly hydroxylated octahedra as in the TOT layer of chlorite, and "OH" for fully hydroxylated octahedra as in the interlayer hydroxide sheet of chlorite. Values are from Chermak and Rimstidt (1989), van Hinsberg et al. (2005), and estimated for $\mathrm{Fe}^{3+}$ in hydroxylated sites (question marks) using the average slope for $\mathrm{Al}^{3+}$ from van Hinsberg et al. (2005).

the 2:1 layer such as cookeite and sudoite) and the scarcity of tri-dioctahedral phyllosilicates (among which the zincosilicate franklinfurnaceite is a rare example, Peacor et al. 1988).

In the octahedral sheet of the 2:1 layer, with a multiplicity of 1 pfu and by analogy with the structure of dioctahedral micas (e.g., muscovite), the M1 site is a more likely target for vacancies than M2, as already proposed by Vidal et al. (2001) for their sudoite end-member. The same analysis indicates that for compositions containing proportions of the "pyrophyllitegibbsite" end-member (proposed by Inoue et al. 2009, and by Trincal and Lanari 2016), with two vacancies, these should be assigned first to M1, then to M4.

A ferric end-member with an octahedral vacancy? Further evidence based on charge distribution may be used to constrain the structure of tentative $\mathrm{Fe}^{3+}$-rich end-members with some di-octahedral character. First, one may simply argue that the exchange due to vacancy creation by substitution of three divalent cations by two trivalent cations is energetically less costly if the trivalent cations compensating the charge deficit are located close to the vacancy (therefore the two trivalent cations should be in the M2 site that has a multiplicity of 2). This is shown in Table 4, which compares a "diferri-sudoite"-type 
TABLE 3.-EXTENDED

\begin{tabular}{|c|c|c|c|c|c|c|c|c|c|c|c|c|c|c|c|c|}
\hline \multirow[t]{2}{*}{ Sample } & \multirow[t]{2}{*}{$\mathrm{Fe}^{3+} / \mathrm{Fe}_{\text {Total }}$} & \multicolumn{14}{|c|}{ Structural formulas normalized to 180} & \multirow{2}{*}{$\begin{array}{c}\mathrm{O}_{10}(\mathrm{OH})_{8} \\
\square\end{array}$} \\
\hline & & Si & $\mathrm{Ti}$ & $\mathrm{Al}$ & ${ }^{\mathrm{IV}} \mathrm{Al}$ & ${ }^{\mathrm{VI}} \mathrm{Al}$ & $\mathrm{Fe}^{2+}$ & $\mathrm{Fe}^{3+}$ & $\mathrm{Mn}$ & $\mathrm{Mg}$ & Alk. $^{a}$ & $\mathrm{H}$ & Eoct. & $X_{\mathrm{Mg}}{ }^{\mathrm{b}}$ & $\square$ & \\
\hline Rat04 & 0.00 & 2.42 & 0.00 & 3.19 & 1.58 & 1.61 & 2.97 & 0.00 & 0.01 & 1.02 & 0.02 & $8.7(4)$ & 5.61 & 0.26 & $0.36(15)$ & $0.20(4)$ \\
\hline CD76 & 0.74 & 2.65 & 0.00 & 2.55 & 1.35 & 1.20 & 0.79 & 2.24 & 0.07 & 1.44 & 0.09 & $6.3(4)$ & 5.74 & 0.65 & $0.17(14)$ & $0.85(2)$ \\
\hline \multirow[t]{3}{*}{ AMC18 } & 0.33 & 2.83 & 0.00 & 2.22 & 1.17 & 1.05 & 2.23 & 1.10 & 0.02 & 1.07 & 0.16 & $7.8(2)$ & 5.47 & 0.32 & $0.37(8)$ & $0.54(1)$ \\
\hline & 0.24 & 2.82 & 0.00 & 2.28 & 1.17 & 1.11 & 2.56 & 0.78 & 0.02 & 1.21 & 0.09 & $7.8(3)$ & 5.67 & 0.32 & $0.24(10)$ & $0.450(4)$ \\
\hline & 0.23 & 2.89 & 0.00 & 2.14 & 1.11 & 1.03 & 2.37 & 0.99 & 0.02 & 1.12 & 0.15 & $7.8(2)$ & 5.53 & 0.32 & $0.32(6)$ & $0.29(3)$ \\
\hline $\mathrm{K} 1130 \mathrm{~B}$ & 0.89 & 3.00 & 0.00 & 3.92 & 1.00 & 2.93 & 0.02 & 0.16 & 0.04 & 1.88 & 0.03 & $7.8(3)$ & 5.02 & 0.99 & $0.95(8)$ & $1.03(2)$ \\
\hline
\end{tabular}

end-member to clinochlore, which has similar $\mathrm{Si} /{ }^{/ \mathrm{v}} \mathrm{Al}$ ratio and a well-established structure (e.g., Rule and Bailey 1987; Smyth et al. 1997; Zanazzi et al. 2006). A large charge mismatch (up to $2 / 3 e$ ) is observed between TOT layer and hydroxide interlayer if trivalent cations incorporated during vacancy creation are not located in the TOT layer, whereas there is no charge mismatch if they are in the TOT layer.

Remaining unknowns include $\mathrm{Al}$ vs. $\mathrm{Fe}^{3+}$ occupancy in the M4 and M2 sites, which is debated (Zheng and Bailey 1989; Smyth et al. 1997; Aja et al. 2015; Inoue and Kogure 2016). The similarly small ionic radii of $\mathrm{Al}$ and $\mathrm{Fe}^{3+}$ (Shannon 1976) make them both candidates for preferential incorporation into the M4 site, as suggested by Vidal et al. $(2006,2016)$.

An "oxychlorite" component. The $\mathrm{R}^{2+}+\mathrm{H}^{+}=\mathrm{Fe}^{3+}$ exchange observed in the $\mathrm{Fe}^{3+}$-rich chlorite samples requires at least one tri-trioctahedral end-member of "oxychlorite" type, i.e., hydrogen deficient. The term oxychlorite (or oxidized chlorite) is infrequently mentioned in the literature, mostly as a petrographic term for a brownish chlorite with higher birefringence than usual, reminiscent of stilpnomelane or Fe-rich vermiculite (e.g., Chatterjee 1966; Rona 1984; Plunder et al. 2015). "Oxychlorite" remains poorly described, does not currently form a group within phyllosilicates or a subgroup within the chlorite group, and its existence has been questioned (in the review of Foster 1962). Yet, the hydrogen-deficient and $14-\AA \AA$ character of such chlorite were established by Chatterjee (1966), but it remains unclear whether the oxidized character is a secondary, alteration feature or a pristine one. The chlorites with the largest $\mathrm{Fe}^{3+}$ contents of our study appear as optically clear, green, unaltered flakes in the hydrothermal vein sample CD76 (Supplemental ${ }^{1}$ Fig. S2) and, in metapelite sample 4ABSC1, as olive-green flakes with some brown edges (Supplemental ${ }^{1}$ Fig. S3), possibly linked to higher $\mathrm{Fe}^{3+} / \mathrm{Fe}_{\text {total }}$ (but evidence is still lacking as $\mathrm{Fe}^{3+} / \mathrm{Fe}_{\text {total }}$ mapping failed due to beam loss). The "oxy-" concept used here for hydrogen-deficient chlorite is the same as that of micas (e.g., Wones 1963; Dyar et al. 1991b, 1993; Virgo and Popp 2000) and other groups of silicates in which some "oxy-members" have

TABLE 4. Atom site and charge (Q) distribution of clinochlore (Nelson and Guggenheim 1993; Smyth et al. 1997; Aja et al. 2015) compared to two tentative magnesian di-ferri-sudoite end-members

\begin{tabular}{|c|c|c|c|c|c|c|}
\hline & $(\mathrm{T} 1)_{2}$ & $(\mathrm{~T} 2)_{2}$ & M1 & $(\mathrm{M} 2)_{2}$ & $(\mathrm{M} 3)_{2}$ & $\mathrm{M4}$ \\
\hline \multirow{3}{*}{ Clinochlore } & $\mathrm{Si}_{2}$ & Si Al & $\mathrm{Mg}$ & $\mathrm{Mg}_{2}$ & $\mathrm{Mg}_{2}$ & $\mathrm{Al}$ \\
\hline & \multicolumn{2}{|c|}{$Q=15$} & \multicolumn{2}{|c|}{$\mathrm{Q}=6$} & \multicolumn{2}{|c|}{$\mathrm{Q}=7$} \\
\hline & $\mathrm{Si}_{2}$ & Si Al & $\square$ & $\mathrm{Mg}_{2}$ & $\left(\mathrm{Fe}^{3+}\right)_{2}$ & $\mathrm{Al}$ \\
\hline \multirow[t]{2}{*}{ Diferri-sudoite } & \multicolumn{2}{|c|}{$Q=15$} & \multicolumn{2}{|c|}{$\mathrm{Q}=4$} & \multicolumn{2}{|c|}{$\mathrm{Q}=9$} \\
\hline & $\mathrm{Si}_{2}$ & Si Al & & $\left(\mathrm{Fe}^{3+}\right)_{2}$ & $\mathrm{Mg}_{2}$ & $\mathrm{Al}$ \\
\hline \multirow[t]{2}{*}{ Diferri-sudoite } & \multicolumn{2}{|c|}{$Q=15$} & \multicolumn{2}{|c|}{$\mathrm{Q}=6$} & \multicolumn{2}{|c|}{$\mathrm{Q}=7$} \\
\hline & \multicolumn{4}{|c|}{ TOT } & \multicolumn{2}{|c|}{$\mathrm{O}$} \\
\hline
\end{tabular}

acquired species status ("oxy-tourmalines" in Henry et al. 2011; "oxo-amphiboles" in Hawthorne et al. 2012). It is noteworthy that Walshe (1986) extracted a set of thermodynamic properties for a $\mathrm{Fe}^{3+}$-rich hydrogen-deficient chlorite end-member along the $\mathrm{R}^{2+}+\mathrm{H}^{+}=\mathrm{Fe}^{3+}$ exchange vector, with composition $\mathrm{Fe}_{4}^{2+} \mathrm{Fe}^{3+} \mathrm{Al}_{2} \mathrm{Si}_{3} \mathrm{O}_{11}(\mathrm{OH})_{7}$. Walshe (1986) estimates the activity of this end-member within a solid solution model as a sole function of the $\mathrm{Fe}^{3+}$ amount. However, this analysis relies on a restricted set of measurements, including analyses originating from Emmons and Larsen (1923) showing contamination by mica, which required correction (see Walshe and Solomon 1981).

Whether due to alteration or not, incorporation of $\mathrm{Fe}^{3+}$ along the $\mathrm{R}^{2+}+\mathrm{H}^{+}=\mathrm{Fe}^{3+}$ exchange vector can be expected to take place in a protonated site, for local charge balance. In the most substituted samples measured in this study (CD76 and 4ASBSC1), about $2 \mathrm{Fe}^{3+}$ are incorporated, and $2 \mathrm{H}^{+}$are lost with respect to standard chlorite. In regard of the chlorite structure (Fig. 1), we suggest that this substitution occurs in the TOT layer (as for hydrogen-deficient mica) rather than in the interlayer hydroxide sheet. In the TOT layer of chlorite, each M1 site shares two hydroxyl groups with M2 sites, whether M1 is filled, cis- or transvacant (see e.g., Sainz-Diaz et al. 2001). Loss of protons from the TOT layer should be energetically more favorable than from the interlayer hydroxide sheet where protons are forming hydrogen bonds with oxygen atoms of the tetrahedral sheets: with proton loss from the hydroxide interlayer, greater loss of symmetry and charge repulsion between the then-unscreened oxygen atoms in tetrahedral sheet and interlayer position are expected, therefore greater crystal strain (which scales positively with the energetic cost of incorporation, Dubacq and Plunder 2018).

\section{Cation site assignment for chlorite solid solutions}

These new constraints suggest the following atom site distribution for chlorite, based on that of Vidal et al. $(2001,2006)$, and including a deprotonation mechanism:

- $\mathrm{Al}$ is distributed first in tetrahedral position ( with $^{\mathrm{T} 2} \mathrm{Al}=4-\mathrm{Si}$ ), which allows for the calculation of octahedral occupancy $\left({ }^{\mathrm{VI}} \mathrm{Al}=\right.$ $\mathrm{Al}_{\text {total }}-{ }^{\mathrm{T} 2} \mathrm{Al},{ }^{\mathrm{M} 1} \mathrm{\square}=6-\Sigma$ oct);

- Proton loss is balanced by $\mathrm{Fe}^{3+}$ (or other trivalent if insufficient $\left.\mathrm{Fe}^{3+}\right)$ in $\mathrm{M} 1$ and $\mathrm{M} 2$ with random distribution $\left(\mathrm{H}_{\text {loss }}^{+}=8-\mathrm{H}^{+}\right.$;

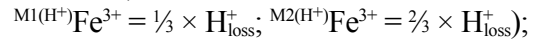

- Trivalent cations compensating the vacancy-induced charge deficiency are distributed in $\mathrm{M} 2\left({ }^{\mathrm{M} 2} \mathrm{R}^{3+}=2^{\mathrm{M} 1} \mathrm{\square}+{ }^{\mathrm{M} 2}\left(\mathrm{H}^{+}\right) \mathrm{Fe}^{3+}\right)$;

- The M2 site is completed with divalents $\left({ }^{\mathrm{M} 2} \mathrm{R}^{2+}=2-{ }^{\mathrm{M} 2} \mathrm{R}^{3+}\right)$;

- The M4 site is filled with trivalent cations and completed with divalent cations if necessary $\left({ }^{\mathrm{M} 4} \mathrm{R}^{2+}=1-{ }^{\mathrm{M} 4} \mathrm{R}^{3+}\right.$, as for the $\mathrm{Al}$-free chlorite end-member);

- Remaining trivalent cations are distributed on M1, then M3 if 

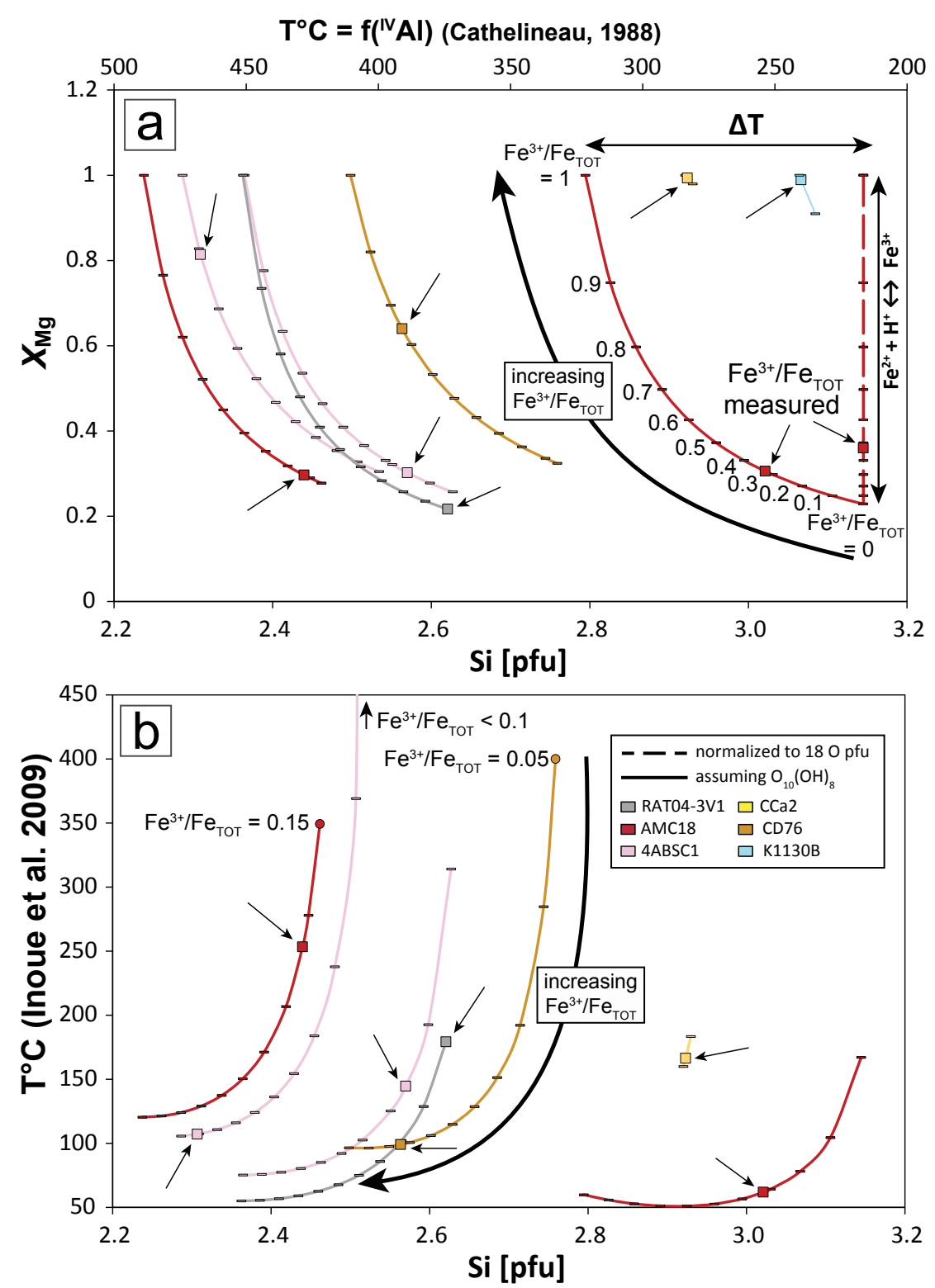

FIGURE 9. Effect of varying $\mathrm{Fe}^{3+} / \mathrm{Fe}_{\text {total }}$ on structural formulas and estimated crystallization temperatures for a selection of $\mathrm{Fe}-$ poor $(\mathrm{CCa} 2$ and $\mathrm{K} 1130 \mathrm{~B})$ and Fe-rich chlorite analyses $\left(\mathrm{Fe}_{\mathrm{TOT}}=\right.$ total $\left.\mathrm{Fe}\right)$. Solid lines are calculated for the $\mathrm{O}_{10}(\mathrm{OH})_{8}$ anionic basis from $\mathrm{Fe}^{3+} / \mathrm{Fe}_{\text {total }}=0\left(\right.$ low $X_{\mathrm{Mg}}$, higher Si content) to $\mathrm{Fe}^{3+} / \mathrm{Fe}_{\text {total }}=1\left(X_{\mathrm{Mg}}=1\right.$, lower Si content). The measured $\mathrm{Fe}^{3+} / \mathrm{Fe}_{\text {total }}$ ratio is shown with a square for each chlorite crystal and highlighted with a black arrow. Note that two analyses are plotted for each of the zoned samples $4 \mathrm{ABSC} 1$ and AMC18. (a) Evolution of $X_{\mathrm{Mg}}$ and Si content with the temperature estimated using the model of Cathelineau (1988). The vertical dashed line shows the effect of proton loss if the anionic basis is allowed to vary, only for sample AMC18 for readability. The $\mathrm{Fe}^{3+} / \mathrm{Fe}_{\text {total }}$ ratio is labeled every $10 \%$ for one of the curves; on every other line $\mathrm{Fe}^{3+} / \mathrm{Fe}_{\text {total }}$ increases by $10 \%$ between black ticks. (b) Evolution of temperature calculated with the model of Inoue et al. (2009) vs. Si content, assuming $\mathrm{O}_{10}(\mathrm{OH})_{8}$ anionic basis. Proton loss alters neither Si content nor temperatures estimated with this model. Chlorite from K1130B (sudoite) is not shown in $\mathbf{b}$ because its vacancy content is out of the applicability range of the Inoue et al. (2009) model. A similar issue appears with some $T$ estimates for $4 \mathrm{ABSC} 1$, where low $\mathrm{Fe}^{3+} / \mathrm{Fe}_{\text {total }}$ values cause zero amesite activity and the infinite constant of the reaction.

necessary $\left({ }^{\mathrm{M} 1+\mathrm{M} 3} \mathrm{R}^{3+}={ }^{\mathrm{V}} \mathrm{R}_{\text {total }}^{3+}-{ }^{\mathrm{M} 4} \mathrm{R}^{3+}-{ }^{\mathrm{M} 2} \mathrm{R}^{3+},{ }^{\mathrm{M} 1} \mathrm{R}^{2+}=1-{ }^{\mathrm{M} 1} \mathrm{R}^{3+}-{ }^{\mathrm{M} 1} \square\right)$;

- $\mathrm{Fe}^{2+}$ and $\mathrm{Mg}$ are distributed following random mixing on all divalent-bearing sites;

- $\mathrm{Fe}^{3+}$ is preferentially incorporated in $\mathrm{M} 4$ over $\mathrm{Al}$, the remaining $\mathrm{Fe}^{3+}$ and $\mathrm{Al}$ are randomly mixed in $\mathrm{M} 1$ and $\mathrm{M} 3$.

The last two steps follow the distribution recommendations of Vidal et al. (2001, 2006, 2016). The new site distribution assumes that the octahedral sum is comprised between 5 and 6 and has been derived in the system $\mathrm{Fe}^{2+}-\mathrm{Fe}^{3+}-\mathrm{Mg}-\mathrm{Al}-\mathrm{Si}-\mathrm{O}-\mathrm{H}$, based on solid solutions with exchange vectors expressed from the "daphnite" end-member. The effect of other cations is not accounted for, although it may be assumed that: (1) tetravalent 
cations such as $\mathrm{Ti}^{4+}$ behave as in biotite where they occur in tetrahedral and octahedral position depending on concentration (e.g., Namur et al. 2009); (2) trivalent cations in the radius range of $\mathrm{Fe}^{3+}$ and $\mathrm{Al}^{3+}$ such as $\mathrm{Cr}^{3+}$ and $\mathrm{Mn}^{3+}$ are globally randomly mixed with the former two; and (3) similarly, divalent cations comparable in size to $\mathrm{Fe}^{2+}$ and $\mathrm{Mg}$ such as $\mathrm{Mn}^{2+}$ are generally randomly mixed.

Improvements compared to the work of Vidal et al. (2001, 2006) consist in (1) differentiated M2 and M3 site distribution for better charge distribution during vacancy creation, (2) allowing for large amounts of $\mathrm{Fe}^{3+}$ in the structure (up to $3 \mathrm{pfu}$ ), (3) considering proton loss, and (4) explicit extension toward the Al-free chlorite end-member.

\section{IMPLICATIONS}

\section{Anionic basis, oxidation state, why bother? Implications for structural formulas and thermobarometry}

The effect of varying $\mathrm{Fe}^{3+} / \mathrm{Fe}_{\text {total }}$ in chlorite on the structural formula and on the estimated temperature of crystallization is quantified and illustrated in Figure 9 for representative samples of this study. The empirical thermometer of Cathelineau (1988, based on Si content pfu, Fig. 9a) and the semi-empirical one of Inoue et al. (2009, based on vacancy, Mg, and Si contents, Fig. $9 b)$ are used on structural formulas with varying $\mathrm{Fe}^{3+} / \mathrm{Fe}_{\text {total }}$, assuming $\mathrm{O}_{10}(\mathrm{OH})_{8}$ basis. Values obtained for measured $\mathrm{Fe}^{3+} / \mathrm{Fe}_{\text {total }}$ ratios are shown as larger squares. The dependency of the temperature estimates and of the structural formulas, taking $\mathrm{Si}$ as an example, is particularly strong for chlorites with high Fe contents (4ABSC1 and AMC18): these evolve from low $X_{\mathrm{Mg}}$ for $\mathrm{Fe}^{3+} / \mathrm{Fe}_{\text {total }}$ $=0$ to $X_{\mathrm{Mg}}=1$ for $\mathrm{Fe}^{3+} / \mathrm{Fe}_{\text {total }}=1$. The Si content decreases by up to 0.3 pfu with increasing $\mathrm{Fe}^{3+} / \mathrm{Fe}_{\text {total }}$, while estimated temperatures increase by $80{ }^{\circ} \mathrm{C}$ with the model of Cathelineau (1988) and decrease by more than $100{ }^{\circ} \mathrm{C}$ with the model of Inoue et al. (2009). For the measured values of $\mathrm{Fe}^{3+} / \mathrm{Fe}_{\text {total }}$, estimated temperatures differ significantly from those obtained assuming that $\mathrm{Fe}$ is entirely reduced or oxidized. In short, both thermometers are in general disagreement for crystallization temperature and the effect of $\mathrm{Fe}^{3+}$ on it. For Fe-poor chlorites, the effect of $\mathrm{Fe}$ speciation is negligible, both on structural formulas and on estimated temperatures ( $\mathrm{CCa} 2$ and $\mathrm{K} 1130 \mathrm{~B}$ in Fig. 9).

Assuming now that proton loss is the sole exchange for $\mathrm{Fe}$ oxidation, and allowing the anionic basis to vary accordingly along $\mathrm{Fe}^{2+}+\mathrm{H}^{+}=\mathrm{Fe}^{3+}$, cations other than $\mathrm{Fe}^{2+}$ and $\mathrm{Fe}^{3+}$ remain unaffected in the structural formula, as shown by a dashed line in Figure 9a. Consequently, as $\mathrm{Fe}^{3+} / \mathrm{Fe}_{\text {total }}$ goes from 0 to $1, X_{\mathrm{Mg}}$ tends to 1 without altering estimated crystallization temperatures (dashed vertical line on Fig. 9a). This result should hold for any thermometer in which $\mathrm{Fe}^{2+}$ content is not involved in the thermometric formulation (note that $X_{\mathrm{Mg}}$ includes $\mathrm{Fe}^{2+}$ content). Conversely, any chlorite thermometer using $\mathrm{Fe}^{2+}$, whether (semi-)empirical or thermodynamic, shall be affected by such Fe oxidation.

\section{Recommendations}

A conclusion of this analysis is that, with increasing Fe content, measuring the oxidation state of iron and the $\mathrm{H}$ content in chlorite becomes increasingly important; chlorite thermometry appears very uncertain (by more than $50^{\circ} \mathrm{C}$ ) when $X_{\mathrm{Mg}}$ is lower than about 0.5 (with all Fe expressed as $\mathrm{Fe}^{2+}$ ). Measurement of $\mathrm{Fe}^{3+}$ content should be systematic when $X_{\mathrm{Mg}}$ obtained by EPMA is below $\sim 0.6$ (with $\mathrm{Fe}$ expressed as $\mathrm{Fe}^{2+}$ ), and proton loss is estimated if ferric iron is measured and above ca. $0.5 \mathrm{Fe}^{3+}$ pfu. To this end, oxygen measurements with EPMA proved reliable and should be generalized (Table 5). In their absence or in case of doubt, assuming that all iron is divalent and using the anionic basis $\mathrm{O}_{10}(\mathrm{OH})_{8}$ has less impact on the calculated structural formula - in terms of, e.g., ${ }^{\text {IV }} \mathrm{Al}$ content and vacancies - than using a (measured) high $\mathrm{Fe}^{3+} / \mathrm{Fe}_{\text {total }}$ ratio but neglecting proton loss, which produces artificial vacancies. However, many thermometers are too sensitive to the octahedral vacancy to justify the neglect of measurement of $\mathrm{Fe}$ oxidation state and $\mathrm{H}$ content for thermobarometry in Fe-rich chlorite.

For thermodynamic modeling of $\mathrm{Fe}^{3+}$ incorporation, at least two ferric end-members are necessary: one with low Fe content (high $X_{\mathrm{Mg}}$ ) where $\mathrm{Fe}^{3+}$ replaces $\mathrm{Al}$, one of the oxychlorite types as suggested by Walshe (1986) but with greater proton loss (with anionic composition $\mathrm{O}_{12}(\mathrm{OH})_{6}$, corresponding to loss of two protons). The need for an additional, di-trioctahedral end-member with high Fe content is debatable, and several end-members are possible. The picture is similar for sudoites: the analysis of Billault et al. (2002) is in favor of a Fe-rich ferric end-member with octahedral sum below 5 , but the anionic basis was not verified, and their analyses align along the possibly artificial substitution creating vacancies. In addition, the $\mathrm{Al}=\mathrm{Fe}^{3+}$ substitution remained important. At the least, an Mg-rich, ferric end-member (with Fe content below $0.5 \mathrm{apfu}$ ) appears necessary for sudoites. Basic thermodynamic modeling and charge-balance considerations provide constraints on the crystal chemistry of $\mathrm{Fe}^{3+}$-rich chlorite,

TABLE 5. Chemical analyzes (median values) of chlorite and their uncertainties based on EPMA ( $O$ measured) and XANES data

\begin{tabular}{|c|c|c|c|c|c|c|c|c|c|c|c|c|c|c|c|c|c|c|c|}
\hline \multirow[t]{2}{*}{ Sample } & \multicolumn{8}{|c|}{ Atom wt\% } & \multirow[t]{2}{*}{$\mathrm{Fe}^{3+} / \mathrm{Fe}_{\text {тот }}$} & \multicolumn{10}{|c|}{ Structural formulas pfu } \\
\hline & $\mathrm{Si}$ & $\mathrm{Al}$ & $\mathrm{Fe}$ & $\mathrm{Mn}$ & $\mathrm{Mg}$ & $\mathrm{Ca}$ & $\mathrm{O}$ & Total & & $\mathrm{Si}$ & $\mathrm{Al}$ & $\mathrm{Fe}^{2+}$ & $\mathrm{Fe}^{3+}$ & $\mathrm{Mn}$ & $\mathrm{Mg}$ & $\mathrm{Ca}$ & $\mathrm{H}$ & $\Sigma$ cat. & $X_{\mathrm{Mg}}{ }^{\mathrm{a}}$ \\
\hline Rat04 & $10.6(2)$ & $13.4(4)$ & $25.9(7)$ & $0.06(8)$ & $3.9(1)$ & - & $44.9(18)$ & 98.8 & 0.0 & $2.42(7)$ & $3.19(9)$ & $2.97(9)$ & 0.0 & $0.01(1)$ & $1.02(3)$ & - & $8.7(7)$ & $9.6(2)$ & $0.255(5)$ \\
\hline CD76 & $11.4(2)$ & $10.5(3)$ & $25.9(7)$ & $0.6(1)$ & $5.3(1)$ & $0.2(1)$ & $43.9(19)$ & 97.7 & $0.74(15)$ & $2.65(7)$ & $2.56(8)$ & $0.8(2)$ & $2.2(2)$ & $0.07(1)$ & $1.44(4)$ & $0.03(1)$ & $6.3(8)$ & $9.8(3)$ & $0.65(6)$ \\
\hline \multirow[t]{3}{*}{ AMC18 } & $12.3(2)$ & $9.3(2)$ & $29.0(7)$ & $0.19(9)$ & $4.0(1)$ & $0.6(2)$ & $44.8(12)$ & 100.7 & $0.33(15)$ & $2.82(5)$ & $2.22(4)$ & $2.2(2)$ & $1.1(2)$ & $0.02(1)$ & $1.07(3)$ & $0.10(2)$ & $7.9(5)$ & $9.6(2)$ & $0.32(2)$ \\
\hline & $10.7(2)$ & $12.0(2)$ & $27.0(7)$ & $0.16(9)$ & $4.7(2)$ & - & $44.1(12)$ & 98.8 & $0.24(15)$ & $2.48(5)$ & $2.89(5)$ & $2.4(2)$ & $0.8(2)$ & $0.02(1)$ & $1.27(3)$ & - & $7.7(5)$ & $9.8(2)$ & $0.35(2)$ \\
\hline & $12.9(2)$ & $8.3(2)$ & 29.1(7) & $0.17(9)$ & $4.4(2)$ & $0.4(2)$ & $44.2(12)$ & 99.4 & $0.23(15)$ & $2.99(5)$ & $2.00(4)$ & $2.6(2)$ & $0.8(2)$ & $0.02(1)$ & $1.19(3)$ & $0.06(2)$ & $7.9(5)$ & $9.7(2)$ & $0.31(2)$ \\
\hline \multirow[t]{5}{*}{ 4ABSC 1} & $10.7(2)$ & $12.6(2)$ & $25.5(7)$ & $0.12(8)$ & $4.7(2)$ & $0.2(1)$ & $43.9(12)$ & 97.8 & $0.91(15)$ & $2.51(5)$ & $3.07(6)$ & $0.3(2)$ & $2.7(3)$ & $0.03(1)$ & $1.28(3)$ & $0.03(1)$ & $5.4(6)$ & $9.9(2)$ & $0.8(1)$ \\
\hline & $10.8(2)$ & $12.3(2)$ & $25.0(7)$ & $0.17(9)$ & $4.7(2)$ & $0.3(1)$ & $44.7(12)$ & 98.0 & $0.59(15)$ & $2.47(5)$ & $2.93(6)$ & $1.2(2)$ & $1.7(2)$ & $0.02(1)$ & $1.26(3)$ & $0.05(1)$ & $7.2(5)$ & $9.6(2)$ & $0.52(4)$ \\
\hline & $10.7(2)$ & $12.5(2)$ & $25.5(7)$ & $0.13(8)$ & $4.6(2)$ & $0.3(2)$ & $44.3(12)$ & 98.0 & $0.44(15)$ & $2.48(5)$ & $3.01(5)$ & $1.7(2)$ & $1.3(2)$ & $0.02(1)$ & $1.24(3)$ & $0.05(1)$ & $7.2(5)$ & $9.8(2)$ & $0.43(3)$ \\
\hline & $10.7(2)$ & $12.3(2)$ & $25.5(7)$ & $0.14(8)$ & $4.7(2)$ & - & $43.9(12)$ & 97.6 & $0.31(15)$ & $2.50(4)$ & $3.00(6)$ & $2.1(2)$ & $0.9(2)$ & $0.02(1)$ & $1.28(3)$ & - & $7.4(5)$ & $9.8(2)$ & $0.38(2)$ \\
\hline & $10.7(2)$ & $12.4(2)$ & $25.8(7)$ & $0.12(8)$ & $4.7(2)$ & - & $44.5(12)$ & 98.4 & $0.27(15)$ & $2.46(4)$ & $3.01(5)$ & $2.2(1)$ & $0.8(1)$ & $0.02(1)$ & $1.24(3)$ & - & $7.9(5)$ & $9.7(2)$ & $0.37(1)$ \\
\hline K1130B & $15.4(2)$ & 19.3(3) & $1.8(2)$ & $0.4(1)$ & $8.3(2)$ & $0.2(1)$ & $52.4(14)$ & 97.8 & $0.89(15)$ & $3.01(5)$ & $3.93(7)$ & $0.02(1)$ & $0.16(2)$ & $0.04(1)$ & $1.88(4)$ & $0.02(1)$ & $7.8(4)$ & $9.1(1)$ & 0.99(1) \\
\hline
\end{tabular}


on the basis of which we recommend the improvements made above to the cation site distribution model of Vidal et al. (2001, 2006). Further targets for improvement relate to the competing distribution of $\mathrm{Al}$ and $\mathrm{Fe}^{3+}$, and to the tetrahedral population of $\mathrm{Fe}^{3+}$-rich end-members, either disilicic or trisilicic - with the thermodynamic properties of $\mathrm{Fe}^{3+}$-rich chlorite, oxychlorite, and their end-members as the ultimate goal.

In other words, this is nothing else than the early recommendation by Dyar et al. (1993) "that attention be focused on characterizing and understanding the highly variable $\mathrm{H}^{+}$and $\mathrm{Fe}^{3+}$ contents of rock-forming silicates, with a goal of establishing accurate stoichiometric bases for those minerals." Twenty-five years later, the challenge is still there for chlorite.

\section{FUNDING}

This work was financially supported by the CNRS INSU programs and by French state funds managed by the ANR within the Investissements d'Avenir program under reference ANR-11-IDEX-0004-02, and more specifically within the framework of the Cluster of Excellence MATISSE led by Sorbonne Université, This research used resources of the Advanced Photon Source, a U.S. Department of Energy (DOE) Office of Science User Facility operated for the DOE Office of Science by Argonne National Laboratory under Contract No. DE-AC02-06CH11357.

\section{ACKNOWLEDGMENTS}

We are grateful to Franck Bourdelle, Loïc Labrousse, Bruno Reynard, and Olivier Vidal for constructive discussion and to Michel Fialin, Nicolas Rividi, Sakura Pascarelli, Olivier Mathon, Antonio Lanzirotti, and Matt Newville for technical advice and support. Thanks are also extended to Rainer Altherr, Guillaume Bonnet, Colette Derré, Anne-Céline Ganzhorn, Michael Jentzer, Loïc Labrousse, Benjamin Lefeuvre, Alexis Plunder, Julien Reynes, Mathieu Soret, and Alberto Vitale-Brovarone for providing some of the chlorite-bearing samples. Constructive reviews by Darby Dyar and Atsuyuki Inoue led to substantial improvements of the manuscript and are gratefully acknowledged.

\section{REFERENCES CITED}

Aja, S.U., and Dyar, M.D. (2002) The stability of Fe-Mg chlorites in hydrothermal solutions-I. Results of experimental investigations. Applied Geochemistry, 17, 1219-1239.

Aja, S., Omotoso, O., Bertoldi, C., Dachs, E., and Benisek, A. (2015) The structure and thermochemistry of three Fe-Mg chlorites. Clays and Clay Minerals, 63, 351-367.

Altherr, R., Soder, C., Meyer, H.-P., Ludwig, T., and Böhm, M. (2017) Ardennite in a high-P/T meta-conglomerate near Vitolište in the westernmost Vardar zone, Republic of Macedonia. European Journal of Mineralogy, 29, 473-489.

Bajt, S., Sutton, S., and Delaney, J. (1994) X-ray microprobe analysis of iron oxidation states in silicates and oxides using X-ray absorption near edge structure (XANES). Geochimica et Cosmochimica Acta, 58, 5209-5214.

Bastin, G.F., and Heijligers, H.J.M. (1989) Quantitative electron probe microanalysis of oxygen, $168 \mathrm{p}$. Eindhoven University of Technology.

Beaufort, D., Rigault, C., Billon, S., Billault, V., Inoue, A., Inoue, S., and Patrier, P. (2015) Chlorite and chloritization processes through mixed-layer mineral series in low-temperature geological systems - a review. Clay Minerals, 50, 497-523.

Billault, V., Beaufort, D., Patrier, P., and Petit, S. (2002) Crystal chemistry of Fe-sudoites from uranium deposits of the Athabasca Basin (Saskatchewan, Canada). Clays and Clay Minerals, 50, 70-81.

Bourdelle, F., and Cathelineau, M. (2015) Low-temperature chlorite geothermometry: a graphical representation based on a T-R ${ }^{2+}-\mathrm{Si}$ diagram. European Journal of Mineralogy, 27, 617-626.

Bourdelle, F., Parra, T., Chopin, C., and Beyssac, O. (2013a) A new chlorite geothermometer for diagenetic to low-grade metamorphic conditions. Contributions to Mineralogy and Petrology, 165, 723-735.

Bourdelle, F., Benzerara, K., Beyssac, O., Cosmidis, J., Neuville, D.R., Brown, G.E., and Paineau, E. (2013b) Quantification of the ferric/ferrous iron ratio in silicates by scanning transmission X-ray microscopy at the Fe $L_{2,3}$ edges. Contributions to Mineralogy and Petrology, 166, 423-434.

Cathelineau, M. (1988) Cation site occupancy in chlorites and illites as a function of temperature. Clay Minerals, 23, 471-485.

Chatterjee, N.D. (1966) On the widespread occurrence of oxidized chlorites in the Pennine zone of the western Italian Alps. Contributions to Mineralogy and Petrology, 12, 325-339.

Chermak, J.A., and Rimstidt, J.D. (1989) Estimating the thermodynamic properties $\left(\Delta G_{\mathrm{f}}^{0}\right.$ and $\left.\Delta H_{\mathrm{f}}^{0}\right)$ of silicate minerals at $298 \mathrm{~K}$ from the sum of polyhedral contributions. American Mineralogist, 74, 1023-1031.

De Andrade, V., Susini, J., Salomé, M., Beraldin, O., Rigault, C., Heymes, T. Lewin, E., and Vidal, O. (2011) Submicrometer hyperspectral X-ray imaging of heterogeneous rocks and geomaterials: Applications at the Fe $K$-edge. Analytical Chemistry, 83, 4220-4227.

De Grave, E., Vandenbruwaene, J., and Van Bockstael, M. (1987) ${ }^{57} \mathrm{Fe}$ Mössbauer Spectroscopic Analysis of Chlorite. Physics and Chemistry of Minerals, 15, 173-180.

Droop, G.T.R. (1987) A general equation for estimating $\mathrm{Fe}^{3+}$ concentrations in ferromagnesian silicates and oxides from microprobe analyses, using stoichiometric criteria. Mineralogical Magazine, 51, 431-435.

Dubacq, B., and Plunder, A. (2018) Controls on trace element distribution in oxides and silicates. Journal of Petrology, 59, 2, 233-256.

Dyar, M.D., Perry, C.L., Rebbert, C.R., Dutrow, B.L., Holdaway, M.J., and Lang, H.M. (1991a) Mössbauer spectroscopy of synthetic and naturally occurring staurolite. American Mineralogist, 76, 27-41.

Dyar, M.D., Colucci, M.T., and Guidotti, C.V. (1991b) Forgotten major elements: Hydrogen and oxygen variation in biotite from metapelites. Geology, 19, 1029-1032.

Dyar, M.D., Guidotti, C.V., Holdaway, M.J., and Colucci, M. (1993) Nonstoichiometric hydrogen contents in common rock-forming hydroxyl silicates. Geochimica et Cosmochimica Acta, 57, 2913-2918.

Dyar, M.D., Delaney, J.S., and Sutton, S.R. (2001) Fe XANES spectra of iron-rich micas. European Journal of Mineralogy, 13, 1079-1098.

Emmons, W.H., and Larsen, E.S. (1923) Geology and ore deposits of the Creede district, Colorado. USGS Bulletin, 718, 198 p.

Evans, K.A., Dyar, M.D., Reddy, S.M., Lanzirotti, A., Adams, D.T., and Tailby, N. (2014) Variation in XANES in biotite as a function of orientation, crysta composition, and metamorphic history. American Mineralogist, 99, 443-457.

Farges, $\mathrm{F}$, Lefrère, $\mathrm{Y}$, Rossano, $\mathrm{S}$, Berthereau, $\mathrm{A}$, Calas, $\mathrm{G}$, and Brown, G.E. (2004) The effect of redox state on the local structural environment of iron in silicate glasses: A combined XAFS spectroscopy, molecular dynamics, and bond valence study. Journal of Non-Crystalline Solids, 344, 176-188.

Fialin, M., Wagner, C., Métrich, N., Humler, E., Galoisy, L., and Bézos, A. (2001) $\mathrm{Fe}^{3+} / \Sigma \mathrm{Fe}$ vs. Fe $L \alpha$ peak energy for minerals and glasses: Recent advances with the electron microprobe. American Mineralogist, 86, 456- 465.

Fiege, A., Ruprecht, P., Simon, A.C., Bell, A.C., Göttlicher, J., Newville, M., Lanzirotti, T., and Moore, G. (2017) Calibration of Fe XANES for high-precision determination of $\mathrm{Fe}$ oxidation state in glasses: Comparison of new and existing results obtained at different synchrotron radiation sources. American Mineralogist, 102, 369-380.

Foster, M. D. (1962) Interpretation of the composition and a classification of the chlorites. U.S. Geological Survey Professional Paper 414-A, p. A1-A33.

Galoisy, L., Calas, G., and Arrio, M.A. (2001) High-resolution XANES spectra of iron in minerals and glasses: structural information from the pre-edge region. Chemical Geology, 174, 307-319.

Garvie, L.A., and Craven, A.J. (1994) Electron-beam-induced reduction of $\mathrm{Mn}^{4+}$ in manganese oxides as revealed by parallel EELS. Ultramicroscopy, 54, 83-92.

Garvie, L.A., Zega, T.J., Rez, P., and Buseck, P.R. (2004) Nanometer-scale measurements of $\mathrm{Fe}^{3+} / \Sigma \mathrm{Fe}$ by electron energy-loss spectroscopy: A cautionary note. American Mineralogist, 89, 1610-1616.

Giles, C., Malgrange, C., Goulon, J., de Bergevin, F., Vettier, C., Fontaine, A., Dartyge, E., and Pizzini, S. (1994) Energy and polarization-tunable X-ray quarter-wave plates for energy dispersive absorption spectrometer. Nuclear Institute and Methods in Physics Research, 349, 622-625.

Hawthorne, F.C., Ungaretti, L., Oberti, R., Caucia, F., and Callegari, A. (1993) The crystal chemistry of staurolite; I, Crystal structure and site populations. The Canadian Mineralogist, 31, 551-582.

Hawthorne, F.C., Oberta, R., Harlow, G.E., Maresch, W.V., Martin, R.F., Schumacher, J.C., and Welch, M.D. (2012) Nomenclature of the amphibole super group. American Mineralogist, 97, 2031-2048.

Henry, D.J., Novák, M., Hawthorne, F.C., Ertl, A., Dutrow, B., Uher, P., and Pezzotta, F. (2011) Nomenclature of the tourmaline supergroup minerals. American Mineralogist, 96, 895-913.

Hillier, S., and Velde, B. (1991) Octahedral occupancy and the chemical composition of diagenetic (low-temperature) chlorites. Clay Minerals, 26, 149-168.

Höfer, H.E., Brey, G.P., Schulz-Dobrick, B., and Oberhänsli, R. (1994) The determination of the oxidation state of iron by the electron microprobe. European Journal of Mineralogy, 6, 407-418.

Holland, T.J.B., and Powell, R. (1998) An internally consistent thermodynamic data set for phases of petrological interest. Journal of Metamorphic Geology, $16,309-343$

Holland, T., Baker, J., and Powell, R. (1998) Mixing properties and activity-composition relationships of chlorites in the system $\mathrm{MgO}-\mathrm{FeO}-\mathrm{Al}_{2} \mathrm{O}_{3}-\mathrm{SiO}_{2}-\mathrm{H}_{2} \mathrm{O}$ European Journal of Mineralogy, 10, 395-406

Inoue, S., and Kogure, T. (2016) High-angle annular dark field scanning transmission electron microscopic (HAADF-STEM) study of Fe-rich 7- $\AA-14-\AA \AA$ interstratified minerals from a hydrothermal deposit. Clay Minerals, 51, 603-613. Inoue, A., Meunier, A., Patrier-Mas, P., Rigault, C., Beaufort, D., and Vieillard, P. 
(2009) Application of chemical geothermometry to low-temperature trioctahedral chlorites. Clays and Clay Minerals, 57, 371-382.

Inoue, A., Inoué, S., and Utada, M. (2018) Application of chlorite thermometry to estimation of formation temperature and redox conditions. Clay Minerals, $53,143-158$.

Lanari, P., Wagner, T., and Vidal, O. (2014) A thermodynamic model for ditrioctahedral chlorite from experimental and natural data in the system $\mathrm{MgO}$ $\mathrm{FeO}-\mathrm{Al}_{2} \mathrm{O}_{3}-\mathrm{SiO}_{2}-\mathrm{H}_{2} \mathrm{O}$ : Applications to P-T sections and geothermometry. Contributions to Mineralogy and Petrology, 167, 1-19.

Lanson, B., Lantenois, S., van Aken, P.A., Bauer, A., and Plançon, A. (2012) Experimental investigation of smectite interaction with metal iron at $80{ }^{\circ} \mathrm{C}$ : Structural characterization of newly formed Fe-rich phyllosilicates. American Mineralogist, 97, 864-871.

Lougear, A., Grodzicki, M., Bertoldi, C., Trautwein, A.X., Steiner, K., and Amthauer, G. (2000) Mössbauer and molecular orbital study of chlorites. Physics and Chemistry of Minerals, 27, 258-269.

Muñoz, M., Vidal, O., Marcaillou, C., Pascarelli, S., Mathon, O., and Farges, F. (2013) Iron oxidation state in phyllosilicate single crystals using Fe-K pre-edge and XANES spectroscopy: Effects of the linear polarization of the synchrotron X-ray beam. American Mineralogist, 98, 1187-1197.

Namur, O., Hatert, F., Grandjean, F., Long, G.J., Krins, N., Fransolet, A.-M., Vander Auwera, J., and Charlier, B. (2009) Ti substitution mechanisms in phlogopites from the Suwalki massif-type anorthosite, NE Poland. European Journal of Mineralogy, 21, 397-406.

Nelson, D.O., and Guggenheim, S. (1993) Inferred limitations to the oxidation of Fe in chlorite: A high-temperature single-crystal X-ray study. American Mineralogist, 78, 1197-1207.

Newville, M. (2014) Fundamentals of XAFS. Reviews in Mineralogy and Geochemistry, 78, 33-74.

Peacor, D.R., Rouse, R.C., and Bailey, S.W. (1988) Crystal structure of franklinfurnaceite; a tri-dioctahedral zincosilicate intermediate between chlorite and mica. American Mineralogist, 73, 876-887.

Pfalzer, P., Urbach, J.-P., Klemm, M., Horn, S., DenBoer, M.L., Frenkel, A.I., and Kirkland, J.P. (1999) Elimination of self-absorption in fluorescence hard-X-ray absorption spectra. Physical Review B, 60, 9335-9339.

Plunder, A., Agard, P., Chopin, C., Pourteau, A., and Okay, A.I. (2015) Accretion, underplating and exhumation along a subduction interface: From subduction initiation to continental subduction (Tavşanlı zone, W. Turkey). Lithos, 226, 233-254.

Raeburn, S.P., Ilton, E.S., and Veblen, D.R. (1997) Quantitative determination of the oxidation state of iron in biotite using X-ray photoelectron spectroscopy: II. In situ analyses. Geochimica et Cosmochimica Acta, 61, 4519-4530.

Rona, P.A. (1984) Hydrothermal mineralization at seafloor spreading centers. Earth-Science Reviews, 20, 1-104

Rule, A.C., and Bailey, S.W. (1987) Refinement of the crystal structure of a monoclinic ferroan clinochlore. Clays and Clay Minerals, 35, 129-138.

Sainz-Diaz, I.C., Hernández-Laguna, A., and Dove, T.M. (2001) Theoretical modelling of cis-vacant and trans-vacant configurations in the octahedral sheet of illites and smectites. Physics and Chemistry of Minerals, 28, 322-331.

Shannon, R.D. (1976) Revised effective ionic radii and systematic studies of interatomic distances in halides and chalcogenides. Acta Crystallographica, $32,751-767$.

Smith, J.V. (1968) The crystal structure of staurolite. American Mineralogist, 53, $1139-1155$

Smyth, J.R., Dyar, M.D., May, H.M., Bricker, O.P., and Acker, J.G. (1997) Crystal structure refinement and Mössbauer spectroscopy of an ordered, triclinic clinochlore. Clays and Clay Minerals, 45, 544-550.

Trincal, V., and Lanari, P. (2016) Al-free di-trioctahedral substitution in chlorite and a ferri-sudoite end-member. Clay Minerals, 51, 675-689.

Tröger, L., Arvanitis, D., Baberschke, K., Michaelis, H., Grimm, U., and Zschech, E. (1992) Full correction of the self-absorption in soft-fluorescence extended X-ray-absorption fine-structure. Physical Review B, 46, 3283-3289.

van Aken, P.A., and Liebscher, B. (2002) Quantification of ferrous/ferric ratios in minerals: New evaluation schemes of $\mathrm{Fe} L_{2,3}$ electron energy-loss near-edge spectra. Physics and Chemistry of Minerals, 29, 188-200.

van Hinsberg, V.J., Vriend, S.P., and Schumacher, J.C. (2005) A new method to calculate end-member thermodynamic properties of minerals from their constituent polyhedra I: Enthalpy, entropy and molar volume. Journal of metamorphic Geology, 23, 165-180.

Vidal, O., Parra, T., and Trotet, F. (2001) A thermodynamic model for Fe-Mg aluminous chlorite using data from phase equilibrium experiments and natural pelitic assemblages in the $100^{\circ} \mathrm{C}$ to $600^{\circ} \mathrm{C}, 1$ to $25 \mathrm{~kb}$ range. American Journal of Science, 301, 557-592.

Vidal, O., Parra, T., and Vieillard, P. (2005) Thermodynamic properties of the Tschermak solid solution in Fe-chlorite: Application to natural examples and possible role of oxidation. American Mineralogist, 90, 347-358.

Vidal, O., De Andrade, V., Lewin, E., Muñoz, M., Parra, T., and Pascarelli, S. (2006) P-T-deformation- $\mathrm{Fe}^{3+} / \mathrm{Fe}^{2+}$ mapping at the thin section scale and comparison with XANES mapping: Application to a garnet-bearing metapelite from the Sambagawa metamorphic belt (Japan). Journal of Metamorphic Geology, 24, 669-683.

Vidal, O., Lanari, P., Muñoz, M., Bourdelle, F., and De Andrade, V. (2016) Deciphering temperature, pressure, and oxygen activity conditions of chlorite formation. Clay Minerals, 51, 615-633.

Virgo, D., and Popp, R.K. (2000) Hydrogen deficiency in mantle-derived phlogopites. American Mineralogist, 85, 753-759.

Walker, J.R., and Bish, D.L. (1992) Application of Rietveld refinement techniques to a disordered IIb Mg-chamosite. Clays and Clay Minerals, 40, 319-322.

Walshe, J.L. (1986) A six-component chlorite solid solution model and the conditions of chlorite formation in hydrothermal and geothermal systems. Economic Geology, 81, 681-703.

Walshe, J.L., and Solomon, M. (1981) An investigation into the environment of formation of the volcanic-hosted Mt. Lyell copper deposits using geology, mineralogy, stable isotopes, and a six-component chlorite solid solution model. Economic Geology, 76, 246-284.

Welch, M.D., and Marshall, W.G. (2001) High-pressure behavior of clinochlore. American Mineralogist, 86, 1380-1386.

White, E.W., and McKinstry, H.A. (1966) Chemical effect on X-ray absorptionedge fine structure. Advances in X-ray Analysis, 9, 376-392.

Wilke, M., Farges, F., Petit, P.E., Brown, J.G., and Martin, F. (2001) Oxidation state and coordination of $\mathrm{Fe}$ in minerals: An Fe $K$-XANES spectroscopic study. American Mineralogist, 86, 714-730.

Wilke, M., Partzsch, G.M., Bernhardt, R., and Lattard, D. (2005) Determination of the iron oxidation state in basaltic glasses using XANES at the K-edge. Chemical Geology, 220, 143-161.

Wones, D.R. (1963) Phase equilibria of "ferriannite," $\mathrm{KFe}_{3}^{+2} \mathrm{Fe}^{+3} \mathrm{Si}_{3} \mathrm{O}_{10}(\mathrm{OH})_{2}$. American Journal of Science, 261, 581-596.

Yamashita, T., and Hayes, P. (2008) Analysis of XPS spectra of $\mathrm{Fe}^{2+}$ and $\mathrm{Fe}^{3+}$ ions in oxide materials. Applied Surface Science, 254, 2441-2449.

Zanazzi, P.F., Montagnoli, M., Nazzareni, S., and Comodi, P. (2006) Structura effects of pressure on triclinic chlorite: A single-crystal study. American Mineralogist, 91, 1871-1878.

Zane, A., Sassi, R., and Guidotti, C.V. (1998) New data on metamorphic chlorite as a petrogenetic indicator mineral, with special regard to greenschist-facies rocks. Canadian Mineralogist, 36, 713-726.

Zazzi, A., Hirsch, T.K., Leonova, E., Kaikkonen, A., Grins, J., Annersten, H., and Edén, M. (2006) Structural investigations of natural and synthetic chlorite minerals by X-ray diffraction, Mössbauer spectroscopy and solid-state nuclear magnetic resonance. Clays and Clay Minerals, 54, 252-265.

Zheng, H., and Bailey, S.W. (1989) Structures of intergrown triclinic and monoclinic II $b$ chlorites from Kenya. Clays and Clay Minerals, 37, 308-316.

\section{Endnote:}

${ }^{1}$ Deposit item AM-19-36766, Supplemental Material and Figure. Deposit items are free to all readers and found on the MSA website, via the specific issue's Table of Contents (go to http://www.minsocam.org/MSA/AmMin/TOC/2019/ Mar2019 data/Mar2019 data.html) 